\title{
An Overview of Key Challenges in the Fabrication of Metal Matrix Nanocomposites Reinforced by Graphene Nanoplatelets
}

\author{
Abdollah Saboori ${ }^{1, *(\mathbb{D})}$, Seyed Kiomars Moheimani ${ }^{2}$, Mehran Dadkhah $^{1}$, Matteo Pavese ${ }^{1}$ (D), \\ Claudio Badini ${ }^{1}$ and Paolo Fino ${ }^{1}$ (D) \\ 1 Department of Applied Science and Technology, Politecnico Di Torino, Corso Duca Degli Abruzzi 24, \\ 10129 Torino, Italy; mehran.dadkhah@polito.it (M.D.); matteo.pavese@polito.it (M.P.); \\ caludio.badini@polito.it (C.B.); paolo.fino@polito.it (P.F.) \\ 2 Department of Materials Engineering, Najafabad Branch, Islamic Azad University, Najafabad 8514143131, \\ Iran; kiomars.moheimani@gmail.com \\ * Correspondence: abdollah.saboori@polito.it; Tel.: +39-011-090-4762
}

Received: 25 January 2018; Accepted: 9 March 2018; Published: 10 March 2018

\begin{abstract}
This article provides an overview of research efforts with an emphasis on the fabrication of metal matrix nanocomposites (MMNCs) reinforced by graphene nanoplatelets (GNPs). Particular attention is devoted to finding the challenges in the production of MMNCs through the powder metallurgy techniques. The main technical challenges can be listed as: (I) reinforcement selection; (II) dispersion of reinforcement within the matrix; (III) reactivity between the reinforcement and matrix; (IV) interfacial bonding; (V) preferred orientation of reinforcement. It is found that some of these difficulties can be attributed to the nature of the materials involved, while the others are related to the preparation routes. It is reported that the challenges related to the process can often be addressed by changing the production process or by using post-processing techniques. More challenging issues instead are related to the composition of the matrix and reinforcement, their reactivity and the dispersion of reinforcement. These topics still bring significant challenges to the materials scientists, and it would be worth mentioning that the fabrication of MMNCs with a uniform dispersion of reinforcement, strong interfacial bonding, without detrimental reactions and improved isotropic properties is still a puzzling issue.
\end{abstract}

Keywords: metal matrix nanocomposite; graphene nanoplatelets; fabrication; dispersion; interfacial bonding; preferred orientation

\section{Introduction}

The last two decades have seen a growing trend towards the development of new materials to fulfil new criteria of working conditions and broaden their applications in various industries such as automotive, aerospace and electronic packaging [1-7]. This growing trend is forced by the progress of technology and consequently by the critical requirements for the working conditions of new devices [8]. The precise requirements for the most suitable type of matrix and reinforcement, and of the processing and post-processing techniques, are however not completely defined [9]. In particular, continuous development of new materials, especially in the nano-size range, always offers new possibilities to the field of metal matrix nanocomposites. For this reason, the relationship between the properties, constituents (matrix, reinforcement, interphases) and the production technique is vital and should be investigated carefully $[10,11]$. This is one of the most interesting topics in the field of metal matrix composites, and this article aims to give its contribution, by reviewing the different materials and 
preparation techniques, always keeping in mind the relationship between the materials, preparation, microstructure and properties.

Among the metal matrix composites, aluminum and magnesium matrix composites are therefore becoming interesting candidates in transportation and aeronautic applications owing to their attractive characteristics such as low density and rather high mechanical strength [4,12-14]. Moreover, aluminum and copper composites are also the main interesting metallic composites in electronic packaging and heat sink applications owing to their simultaneous high thermal and electrical conductivity and proper specific strength [15-17].

On the other hand, graphene, which is a one atom-thick planar sheet of $\mathrm{sp}^{2}$-bonded carbon atoms, has attracted tremendous attention in recent years [18-22]. With respect to the carbon nanotube, which is one-dimensional reinforced graphene, it is much easier to control and disperse in the metal matrix. In recent research, it has been employed mainly as a 2D reinforcement in polymer matrix composites due to its extraordinary characteristics such as high thermal and electrical conductivity, low density and very high specific strength. Nonetheless, up to now, far too little attention has been paid to the use of graphene as an ideal reinforcing material in metal matrix composites. Thus, another target of this work is to review the effect of graphene nanoplatelets on the electrical conductivity and mechanical performance of metal matrix composites, in particular aluminum, magnesium and copper matrix composites.

Weight and specific strength are two critical design parameters in automotive and aerospace industries, and they should essentially be taken into account in the design of new composite materials [23-26]. In fact, transportation industries (automotive and aerospace) are faced with new challenges about the reduction of fuel consumption. Hence, magnesium and aluminum alloys and their composites have received considerable attention in research institutes and industries to satisfy these new challenges $[27,28]$. The main merits of magnesium and aluminum are their low density, availability and machinability. Thus, there is a growing body of literature on the fabrication and characterization of magnesium-based and aluminum-based composites with a high specific strength to be used at moderate temperatures.

Apart from the development of new composite materials, it has been proven that the strengthening of an alloy can be achieved through the heat treatment processes [11,29]. However, it is reported that the heat treatment processes cannot be a proper way of strengthening for alloys working at moderate and high temperatures.

In addition to the structural applications, electronic packaging industries need new materials with high thermal conductivity, a tailored coefficient of thermal expansion and proper mechanical strength to satisfy the common issues in this field and increase the efficiency of devices. Copper, because of its very high thermal and electrical conductivity, is one of the interesting candidates that can be used in this area. However, its high coefficient of thermal expansion and moderate mechanical strength limited its applications in electronic packaging and heat sink applications. Therefore, this paper seeks to review the possible solutions that will help to address these challenges and fabricate a new copper composite material with desirable properties.

Apart from the positive effects of graphene nanoplatelets (GNPs) on the mechanical and thermophysical properties of metal matrix nanocomposites such as aluminum matrix nanocomposites, GNPs can also improve the tribological behavior of MMNCs. Traditionally, two approaches have been used to improve the tribological performance of aluminum alloys: using liquid or grease lubricants or applying solid lubricant coatings. However, these traditional techniques have some drawbacks that limit the application of aluminum alloys in abrasive environments. Thus, MMNCs reinforced by GNPs have been developed to overcome the drawbacks and consequently improve the wear resistance and tribological behavior of MMNCs [7,9].

Overall, based on theoretical considerations, it can be concluded that the introduction of GNPs into a metal matrix can simultaneously improve its mechanical characteristics, thermal and electrical conductivities and reduce its coefficients of friction and thermal expansion. Nevertheless, 
the fabrication of metal matrix composites is faced with several technical challenges, which should be addressed prior to or during the fabrication process to be successful in taking advantage of the superior features of the reinforcement within the metal matrix. The main technical challenges can be listed as follows: (I) reinforcement selection; (II) dispersion of reinforcement within the matrix; (III) reactivity between the reinforcement and matrix; (IV) interfacial bonding; (V) preferred orientation of reinforcement (Table 1). Indeed, a great deal of previous research and review papers have focused on the application of GNPs in the MMNCs and studied the effect of GNPs on the properties of the MMNCs $[7,9,30]$.

Table 1. The technical challenges in the fabrication of metal matrix nanocomposites (MMNCs) reinforced with graphene nanoplatelets (GNPs).

\begin{tabular}{llll}
\hline \multicolumn{1}{c}{ Challenge } & \multicolumn{1}{c}{ Source } & \multicolumn{1}{c}{ Role } & \multicolumn{1}{c}{ Solution(s) } \\
Selection of high-quality GNPs & $\begin{array}{l}\text { Lack of data from } \\
\text { suppliers }\end{array}$ & $\begin{array}{l}\text { Defects play key roles in the } \\
\text { reactivity and also the final } \\
\text { mechanical properties }\end{array}$ & $\begin{array}{l}\text { Characterizing as-received GNPs in } \\
\text { terms of residual defects and } \\
\text { morphology }\end{array}$ \\
\hline Uniform dispersion of GNPs & $\begin{array}{l}\text { A van der Waals force } \\
\text { between the platelets }\end{array}$ & $\begin{array}{l}\text { Agglomerates of GNPs leave } \\
\text { some porosities and are } \\
\text { deleterious for all the properties }\end{array}$ & $\begin{array}{l}\text { Using a novel wet mixing technique } \\
\text { for mixing and the powder } \\
\text { metallurgy method for production }\end{array}$ \\
\hline Reactivity with matrix & $\begin{array}{l}\text { Residual defects in GNPs } \\
\text { and the molten state of } \\
\text { the matrix }\end{array}$ & $\begin{array}{l}\text { Carbide formation in Al/GNPs } \\
\text { system is deleterious for the final } \\
\text { properties }\end{array}$ & $\begin{array}{l}\text { Using a novel wet mixing method } \\
\text { for dispersion, using GNPs with the } \\
\text { lowest level of defects, employing } \\
\text { powder metallurgy techniques for } \\
\text { production }\end{array}$ \\
\hline $\begin{array}{l}\text { Interfacial bonding between } \\
\text { metal/GNPs }\end{array}$ & $\begin{array}{l}\text { Poor } \\
\text { adhesion/wettability } \\
\text { between metal matrix } \\
\text { and GNPs }\end{array}$ & $\begin{array}{l}\text { Poor interfacial bonding results in } \\
\text { poor mechanical and } \\
\text { thermophysical properties }\end{array}$ & $\begin{array}{l}\text { Coating of GNPs or using } \\
\text { post-processing techniques to } \\
\text { remove the voids from the interface } \\
\text { of metal/GNPs }\end{array}$ \\
\hline Alignment/orientation of GNPs & $\begin{array}{l}\text { High aspect ratio of } \\
\text { GNPs (1:10-1:100) }\end{array}$ & $\begin{array}{l}\text { The preferred orientation of GNPs } \\
\text { results in anisotropy properties }\end{array}$ & $\begin{array}{l}\text { Using hot isostatic pressing instead } \\
\text { of unidirectional consolidation }\end{array}$ \\
\hline
\end{tabular}

However, far too little attention has been paid to the main challenges in the fabrication of GNP-reinforced MMNCs, and so in this paper, several efforts that have been undertaken to produce new metal matrix nanocomposites with the aim of not only meeting these challenges, but also increasing the performance of composites have been reviewed.

\section{Metal Matrix Nanocomposites}

Composites, which are new materials that can be fabricated from more than two constituents with various chemical, physical and mechanical properties, have superior properties in comparison with a monolithic metal matrix [31,32]. In fact, through the fabrication of composites, it would be possible to reduce the specific gravity, improve the mechanical properties and in some cases, depending on the reinforcement, enhance the thermal and electrical conductivities with respect to the traditional materials $[33,34]$.

In principle, based on the matrix, composite materials can be categorized into three main groups; metal matrix composites (MMC), ceramic matrix composites (CMC) and polymer matrix composites (PMC) [31]. Generally speaking, metal matrix composites exhibit better properties in comparison with ceramic and polymer-based composites. In fact, MMCs have a lower coefficient of thermal expansion and higher thermal and mechanical properties with respect to PMCs. On the other hand, their mechanical properties (i.e., toughness, plastic deformation) are not comparable to CMCs [32,35,36].

In structural applications, the matrix usually is a light metal like aluminum, magnesium or titanium, which is reinforced by dispersed ceramic particles or fibers, while in electronic applications, copper and copper alloys are common [31].

The presence of reinforcement within a metal matrix not only affects the mechanical properties, but also changes the physical properties of composites such as wear resistance, thermal conductivity or the friction coefficient [37]. Regarding the type of reinforcement, it should be noticed that the 
reinforcement could be either continuous or discontinuous. MMCs with discontinuous reinforcement being isotropic materials, can be processed with the common metalworking techniques such as forging, rolling or extrusion. Continuous reinforcements are mostly fibers, for instance carbon fiber, which can be used in metal matrix nanocomposites to fabricate an anisotropic MMC due to the specific alignment of fibers [37].

To fabricate a metal matrix composite, a reinforcement is dispersed within a metal matrix to gain a significant improvement in its properties with respect to the monolithic metal matrix. In some cases, for instance in $\mathrm{Al}$ composite reinforced with a carbonic material, before fabrication of the composite, the carbonic reinforcement is coated to prevent any deleterious chemical reaction between the matrix and the reinforcement [38].

As mentioned earlier, several metal matrices have been used for the fabrication of MMNCs. In particular, $\mathrm{Al}$ [39-42] and $\mathrm{Mg}$ [13,43,44] matrix nanocomposites have attracted more attention in the field of structural applications thanks to their weight and strength to weight characteristic, while copper [45-47] matrix nanocomposites exhibit promising properties for being used in the field of electronic packaging applications.

According to the literature, aluminum matrix nanocomposites (AMNCs) consist of aluminum or its alloys as a matrix together with ceramic particles or some fibers as dispersed reinforcement. In fact, aluminum matrix nanocomposites are very interesting because of their comparative advantages such as good mechanical properties, good processability and low price [48]. The typical properties of Al matrix nanocomposites can be defined as high strength, high stiffness, low density, high thermal and electrical conductivities [32]. Over the last decade, the development of new lighter and high-performance metal matrix nanocomposites has been of great interest and has led to the rapid development of AMNCs [9].

Copper matrix nanocomposites thanks to their higher thermal conductivity, lower coefficient of thermal expansion and higher mechanical properties with respect to the other conductive MMNCs can satisfy the electrical packaging requirements [49,50].

Another interesting metal matrix is magnesium, which is the lightest metal with a density of $1.74 \mathrm{~g} / \mathrm{cm}^{3}$. It is used as an ideal matrix to produce the light $\mathrm{Mg}$-based nanocomposites with improved mechanical properties to be used in automotive and aerospace applications [51,52].

To sum up, it can be concluded that MMNCs can be produced through the combination of a soft metal matrix with a strong reinforcement to obtain the following properties:

- Higher mechanical properties

- Lower specific gravity

- Improved elevated temperature properties

- Better thermal expansion coefficient

- Higher thermal conductivity

- Higher wear resistance

- Improved damping capabilities

Apart from the final properties, the main drawbacks of MMNCs are the relatively high cost of production and reinforcement. Thus, cost-effective processes such as conventional powder metallurgy need to be developed.

\section{Reinforcement (First Challenge)}

Different types of reinforcements with different features are available to be employed in MMNCs, in particular in aluminum-, copper- and magnesium-based composites. Basically, the selection of reinforcement is carried out depending on the metal matrix, fabrication process and desired properties.

The main required characteristics of reinforcement based on the application of the composite can be a combination of some of the following properties; comparatively low specific gravity, high Young's modulus, high strength, chemical and mechanical compatibility with the matrix, high thermal and electrical conductivity and low coefficient of thermal expansion [53]. In principle, as discussed earlier, 
aluminum is rather light, and its modulus is somewhat low, while its strength is not high enough. Moreover, its coefficient of thermal expansion is rather high, while its electrical and thermal properties are medium. Therefore, to develop a new aluminum-based composite with higher mechanical and physical properties and a desirable low coefficient of thermal expansion, high strength and high modulus, at least a proper reinforcement is essentially required. So as to widen the application of aluminum and copper in electronic packaging industries and fulfil the criteria in this field, using very high thermal conductive reinforcements with a low thermal expansion coefficient is essential. Meanwhile, the selected reinforcement should be light enough to keep the composite as light as possible. In the case of magnesium alloys, as discussed earlier, the main drawback is their mechanical properties, in particular at elevated temperatures. Thus, these characteristics should be improved. Under these circumstances, inorganic ceramic particles or carbon-based reinforcing materials can be used as reinforcements to develop new composite materials with superior mechanical, physical and thermal properties.

Table 2 compares the characteristics of the different reinforcements that can be used in MMNCs. By considering the high strength, high hardness, high thermal and electrical conductivity and rather low density, graphene nanoplatelets (GNPs) have been chosen as the reinforcement in several recent studies.

Table 2. The characteristics of common reinforcements, data from [54-58].

\begin{tabular}{|c|c|c|c|c|c|c|}
\hline Material & Density $\left(\mathrm{g} / \mathrm{cm}^{3}\right)$ & $\begin{array}{l}\text { Thermal Conductivity } \\
(\mathrm{W} / \mathrm{m} \cdot \mathrm{K})\end{array}$ & $\begin{array}{l}\text { Thermal Expansion } \\
\text { Coefficient (106/K) }\end{array}$ & $\begin{array}{l}\text { Melting } \\
\text { Point }\left({ }^{\circ} \mathrm{C}\right)\end{array}$ & $\begin{array}{c}\text { Vickers } \\
\text { Hardness (HV) }\end{array}$ & $\begin{array}{c}\text { Elastic } \\
\text { Modulus (GPa) }\end{array}$ \\
\hline$\alpha-\mathrm{Al}_{2} \mathrm{O}_{3}$ & $3.95-3.98$ & $35-39$ & $7.1-8.4$ & $2054-2072$ & $1800-3000$ & $365-393$ \\
\hline AlN & $3.05-3.26$ & $130-180$ & $2.5-5.3$ & $2200-2230$ & $1170-1530$ & $308-346$ \\
\hline$\alpha-\mathrm{SiC}$ & 3.15 & $42.5-270$ & $4.3-5.8$ & $2093-2400$ & $2400-2500$ & $386-476$ \\
\hline$\beta-\mathrm{SiC}$ & 3.16 & 135 & 4.5 & 2093 decom. & 2700 & $262-468$ \\
\hline Diamond & 3.52 & 2400 & - & 3550 & 8000 & 930 \\
\hline Graphite & 2.25 & $25-470$ & $0.6-4.3$ & - & - & $4.8-27$ \\
\hline SWCNTs & 1.8 & Up to 2900 & Negligible & - & - & 1000 \\
\hline GNPs & $1.8-2.2$ & 5300 & $-0.8-0.7$ & - & - & 1000 \\
\hline
\end{tabular}

Notes: “decom." represents decomposes.

\section{Graphene Nanoplatelets}

A single layer of graphene, which is a single 2D layer of carbon atoms with a strong $\mathrm{sp}^{2}$ band in a honeycomb lattice, was created in 2004 [59]. Figure 1 shows various allotropes of nanoscale graphitic materials consisting of graphite, graphene, nanotubes and fullerene.

The remarkable characteristics of graphene such as an elastic modulus of $1 \mathrm{TPa}$, a strength of $130 \mathrm{GPa}$, a thermal conductivity of $5300 \mathrm{~W} / \mathrm{m} \cdot \mathrm{K}$, an electrical conductivity of $6000 \mathrm{~S} / \mathrm{cm}$ and an ultra-high surface area make it a very interesting material to be used in different applications [60]. In fact, these fabulous properties persuade researchers to consider this material as an ideal reinforcement in MMNCs to develop new composite materials with extraordinary properties. This means that through the addition of graphene to a metal matrix, it can be possible to achieve superior properties that could be exploited in various industries such as aerospace, automotive, electronics, energy, structural and mechanical, environmental.

Since 2004, several papers have been published on graphene and graphene composites, and as can be seen in Figure 2, the number of publications on graphene in Science-Direct increased exponentially to several thousands of papers (more than 65,000). Thus, by increasing the application of graphene, several research works have focused on its production. In general, graphene can be produced by two different approaches; top-down and bottom-up. Epitaxial growth techniques [61], chemical vapor deposition (CVD) [62] and unzipping of carbon nanotubes [63] are the bottom-up techniques, whereas exfoliation of graphite is the top-down method [64]. As a matter of fact, graphene nanoplatelets with a platelet morphology include some graphene sheets that are bonded to each other by interatomic van der Walls force. Generally speaking, it is shown that the characteristics of graphene nanoplatelets in 
the van der Walls bonding direction are remarkably different from those displayed inside the graphitic planes [65].

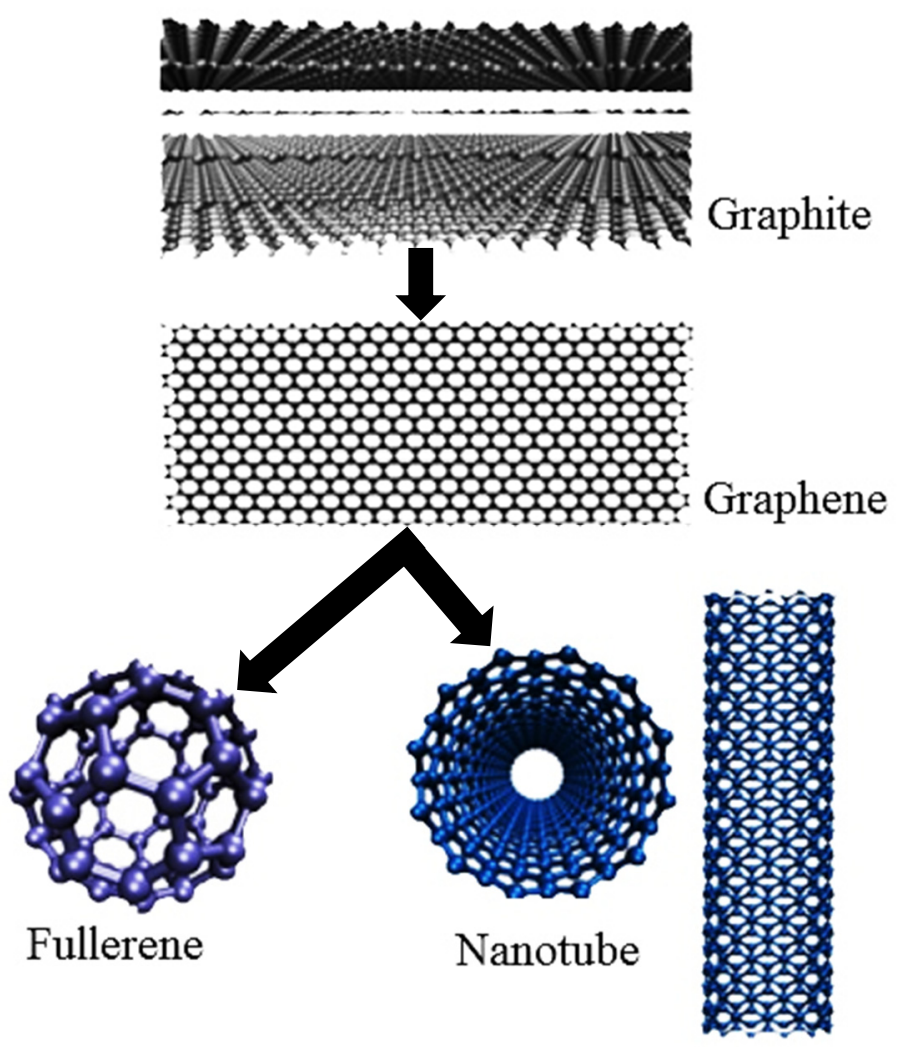

Figure 1. Different allotropes of carbon: 3D graphite, 2D graphene, $1 \mathrm{D}$ carbon nanotubes and 0D carbon fullerenes.

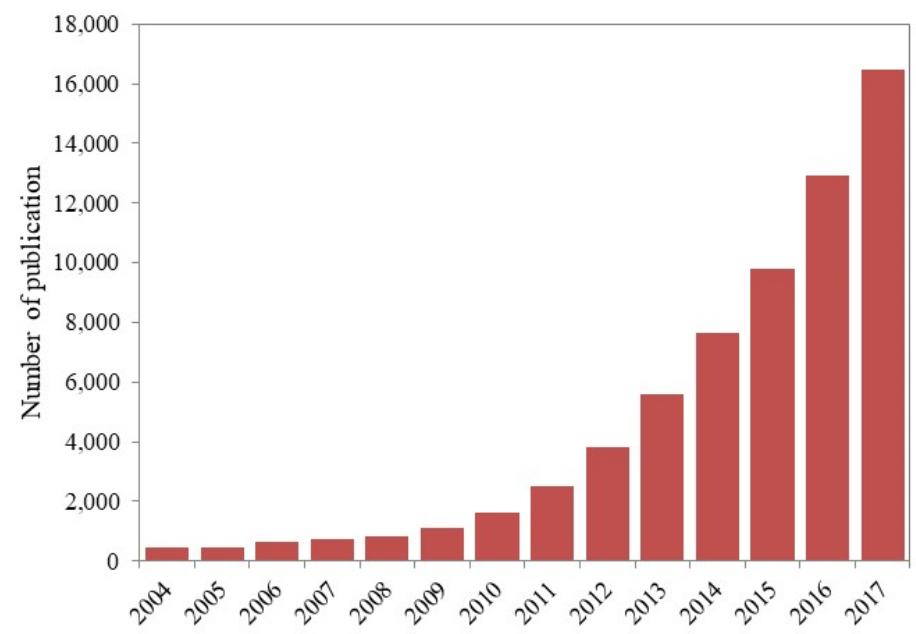

Figure 2. Publication trend in graphene chorology between 2004 and 2017 in Science-Direct (this graph is plotted based on the simple searching of "graphene" at: www.sciencedirect.com).

The production of graphene nanoplatelets like the production of single-layer graphene is categorized into two approaches; top-down and bottom-up. In the top-down approach, GNPs are produced by an incomplete exfoliation process whereas, in the bottom-up approach, they can be produced by bonding the single layers of graphene on top of each other [64]. Some advantages such as 
higher stability, lower production cost, ease of handling and more versatility in size and aspect ratio of GNPs with respect to the single layer of graphene make them very desirable fillers in MMNCs. As a matter of fact, the high aspect ratio graphene nanoplatelets within a matrix can form a 3D network and anisotropic properties, even at rather low content [66,67], and as a consequence, the thermal and electrical conductivities can be improved, as well as the mechanical properties. However, because of the presence of a huge number of GNP suppliers on the market for the production of GNPs, from small enterprises to international companies, the selection of a proper supplier and its GNPs is somewhat difficult. Moreover, because of the size of graphene with a typical diameter from some nanometers (single-layer graphene) to some hundred nanometers in multilayer graphene, it is somewhat difficult to have precise datasheets of graphene from suppliers. In fact, due to these difficulties, direct access to the real properties of graphene is very difficult. Thus, it is recommended to characterize the raw graphene to determine the real characteristics of graphene. However, traditional analytic equipment has insufficient resolution to determine the mechanical, electrical and thermal properties of nanometric graphene. Therefore, some advanced characterizations are required for any raw graphene nanoplatelets to know their real properties. However, even in the case of advanced characterizations, in spite of using scanning electron microscopy (SEM), X-ray diffraction (XRD) and Raman analysis to determinate the average aspect ratio, amorphous carbon phases, residual defects and numbers of graphene layers, the mechanical, electrical and thermal properties' evaluation of raw graphene is rather difficult.

\section{Preparation of MMNCs Reinforced by GNPs}

Along with the development of MMNCs, several endeavors have been carried out on the development of innovative fabrication techniques to elaborate MMNCs. Thus, it would be possible to find several fabrication processes to produce the metal matrix nanocomposites. The choice of fabrication technique depends on the final shape of MMNCs, the reinforcement content and distribution, the envisaged application and finally the fabrication expenses. Generally speaking, these techniques are divided into two main categories: liquid processes and solid processes. Previously published works have shown that poor wettability between the molten metal and reinforcing particles is a key challenge in the fabrication of MMNCs, and it limits the liquid-based processes. Therefore, to address this problem, solid-state processing has been developed to elaborate the MMNCs. Since this approach is based on the processing of metallic powder, this category of fabrication of MMNCs is also known as powder metallurgy (PM) methods. The PM process starts from the mixing of starting powders (matrix and reinforcing particles), then continues with the consolidation of powder mixtures and finally involves the sintering of the compacted components.

\subsection{Dispersion of GNPs (Second Challenge)}

Dispersion of GNPs within the metallic matrices is challenging owing to the presence of a van der Waals force between the platelets [11]. Therefore, in the literature, dispersion of graphene within the different metal matrices has been carried out by several strategies such as mechanical dispersion, molecular-level mixing, advanced mixing based on coated reinforcement and dispersion in solvents with ultrasonic supports. Bartolucci et al. have used ball milling as the mixing method to disperse graphene within the aluminum matrix [68]. In fact, in their work, Al-GNP composite powder was blended and after that milled by means of a high energy attritor. It is found that by using high energy ball milling, not only a homogenous dispersion of GNPs within the composite can be achieved, but also the nascent oxide layer forms on the surface of aluminum particles. Prez-Bustamante et al. have also reported that it is possible to obtain a homogeneous distribution of GNPs within the aluminum matrix using a high energy ball milling [5]. Moreover, it is found that by increasing the milling time, the graphene nanoplatelets are embedded inside the aluminum particles and accordingly postpone the formation of an amorphous structure in graphene.

Rashad et al. have introduced a novel wet mixing technique to disperse the GNPs within the $\mathrm{Mg}-\mathrm{Al}$ alloy (Figure 3) [1]. This novel mixing method consists of ultrasonication of powder and 
GNPs separately followed by dropwise addition of GNPs solution into the powder slurry, mechanical agitation of the mixture and finally vacuum drying overnight at $70^{\circ} \mathrm{C}$.

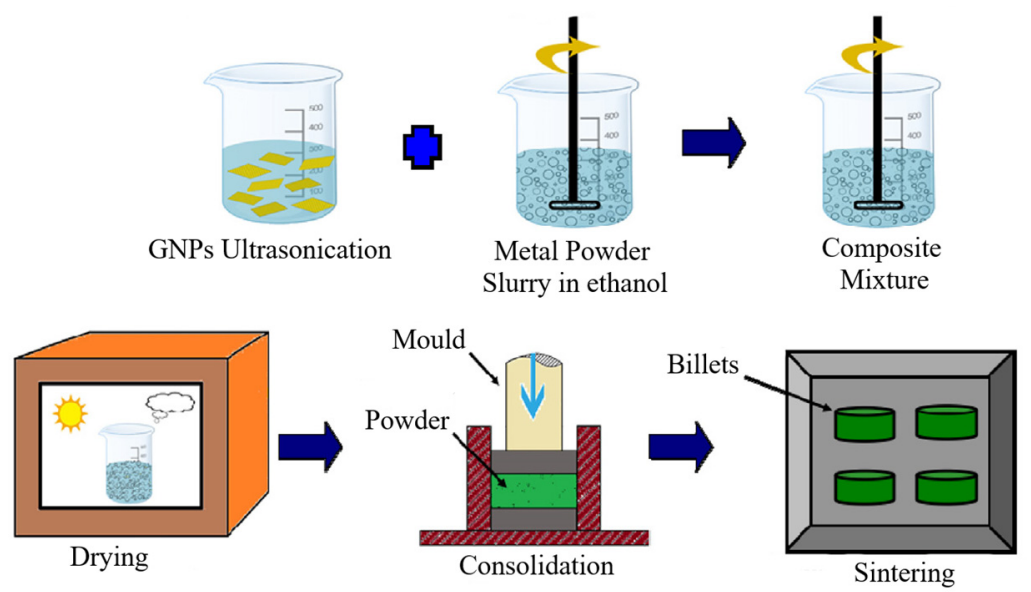

Figure 3. Flowchart of the semi-powder method.

They have found that GNPs are homogeneously dispersed within the matrix. Saboori et al. have compared the dispersion of GNPs within the copper matrix, which is achieved by the wet mixing method and ball milling techniques [69]. They have found that despite the uniform dispersion of GNPs within the matrix, two undesirable phenomena, the introduction of defects into the carbon lattice and crystal size reduction of GNPs, have taken place during the ball milling. On the other hand, their Raman spectroscopy analysis (Table 3) together with the microstructural evaluations show that by using the wet mixing method, apart from a uniform dispersion of GNPs that can be achieved, the structure of GNPs can remain unchanged in comparison with the starting GNPs.

Table 3. Raman data of GNPs before and after wet mixing and ball milling, data from [69].

\begin{tabular}{ccccc}
\hline \multirow{2}{*}{$\begin{array}{c}\text { Composition } \\
\text { (Cu-GNPs) }\end{array}$} & Ball Milled & Wet Mixed & Ball Milled & Wet Mixed \\
\cline { 2 - 5 } & 0.112 & 0.112 & 0.511 & 0.511 \\
Before mixing & 0.893 & 0.127 & 0.584 & 0.525 \\
After mixing & \multicolumn{2}{c}{$\boldsymbol{I}_{D} / \mathbf{I}_{G}$} & $\mathbf{I}_{2 D} / \mathbf{I}_{G}$ \\
\hline
\end{tabular}

In another work, Saboori et al. have used the wet mixing technique to disperse the graphene nanoplatelets within the aluminum matrix [70]. It is found that the wet mixing method, even in this case, has a great capacity to be employed for dispersing the GNPs. Figure 4 shows the homogeneous distribution of graphene nanoplatelet within the aluminum matrix.
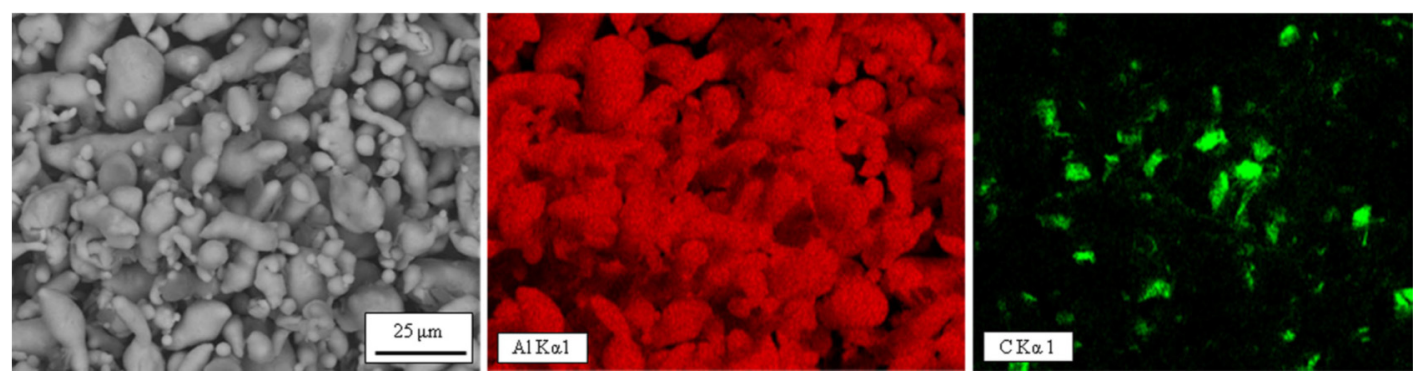

Figure 4. Energy- dispersive X-ray spectroscopy (EDS) maps of Al-1 wt. \% GNP composite after mixing by the wet mixing technique, reproduced from [70], with permission from Springer Nature, 2017. 
Chen et al. analyzed the microstructure of $\mathrm{Cu} / \mathrm{GNPs}$ nanocomposite produced by the combination of the molecular-level mixing technique and the spark plasma sintering (SPS) process [17]. In the evaluation of the graphene structure before and after mixing, they have found that neither $I_{\mathrm{D}} / I_{\mathrm{G}}$ nor $I_{2 \mathrm{D}} / I_{\mathrm{G}}$ were altered after the composite preparation, which indicates that during the fabrication process, there was no defect introduced into the structure of GNPs.

Hwang et al. have proposed a molecular-level mixing method to achieve a uniform dispersion of graphene within a metal matrix [71]. Indeed, this method is suggested to avoid the issues of distribution and thermal damage of graphene flakes during the synthesis of MMNCs reinforced by graphene. In this work, it is claimed that during the molecular level mixing process, strong adhesion energy between graphene and copper is formed. It is found that the functional groups such as hydroxyl, epoxide, carbonyl and carboxyl, which are present in reduced graphene oxide (RGO), can improve the bonding between graphene and metals by covalent oxygen bonds. The schematic diagram of their fabrication method is shown in Figure 5.
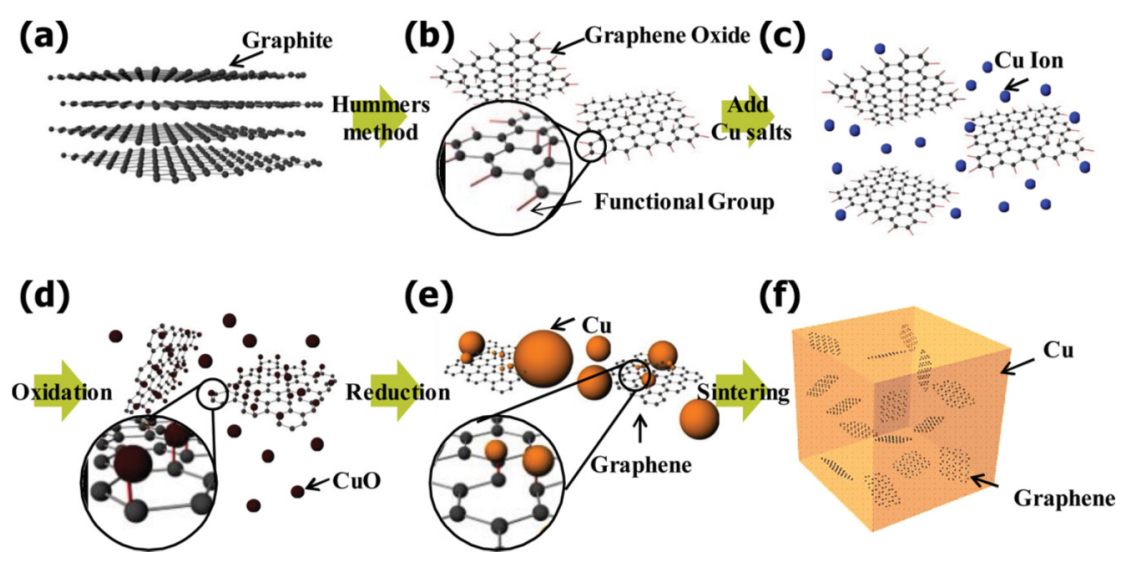

Figure 5. Schematic of the preparation method of RGO/Cu nanocomposite: (a) pristine graphite; (b) graphene oxide by the Hummers method; (c) dispersion of copper salt in graphene oxide solution; (d) oxidation of copper ions to copper-oxide on graphene oxide; (e) reduction of copper-oxide and graphene oxide; (f) sintered RGO/Cu nanocomposite powders, reproduced from [71], with permission from from John Wiley and Sons, 2013.

Apart from the aforementioned techniques of dispersion, an advanced dispersion process based on coated reinforcement is developed that resulted in a good dispersion of GNPs within the matrix. In addition, this advanced process avoids severe mixing and milling processes. Generally speaking, this coating process includes surface modification of the reinforcement and the increment of active surface sites to improve the adhesion between the matrix and the reinforcement. This coating process can be performed by electroless methods [72-74], CVD [75,76] and PVD [77,78] methods. However, it should be noted that the coating of the reinforcement introduces additional impurities and oxides into the final consolidated materials.

All in all, the research findings show that despite all the potentials of ball milling and advanced dispersion process on the basis of coated reinforcement in a uniform dispersion of ceramic particles within the metallic matrices, these methods are not the proper techniques for the dispersion of GNPs. The novel wet mixing method shows great potential to be used as an appropriate method of mixing. In fact, a large amount of research has shown that a uniform dispersion of GNPs without introducing any structural defect can be achieved through the wet mixing method [79-81].

\subsection{Consolidation and Sintering (Third Challenge)}

Based on the state of the matrix during the production, the fabrication techniques are divided into two groups; liquid state and solid state techniques. However, due to the poor wettability of GNPs 
with molten metals, which results in a non-uniform dispersion of GNPs, the liquid state methods have not been employed to fabricate the MMNCs reinforced with GNPs. Therefore, in the following section, the main challenges related to the fabrication of metal/GNPs nanocomposites produced by powder metallurgy techniques are described.

Basically, in the production of MMNCs using PM techniques, the reinforcement and matrix are mixed together and then consolidated in a die. The literature describes that press-sintering process is only a feasible technique if a low GNPs content is used in the composite. Otherwise, consolidation during sintering will be challenging [82,83]. For MMNCs with GNP content higher than 4 vol \%, to reach full densification, an external pressure assisted method should be used. Previous research has established that hot pressing is a well-known technique to fabricate fully-dense MMNCs with high GNP content. Nevertheless, one of the main advantages of the press-sintering process is the possibility to fabricate a net shaped or near net shaped component without any post-machining. Thus, in this category of MMNC production, one of the key steps that can affect the final characteristics of composites is compaction. Therefore, studying the compaction behavior of composites reinforced by nano-reinforcing materials is of great interest. Several attempts have been made to find the compaction equations to estimate the relative density at a specific applied pressure. Balshin and Mettalprom [84], Heckel [85], Walker [86], Copper-Eaton [87], Kawakita [88], Panelli and Ambrosio Filho [89] and Ge [90] introduced the most famous compaction equations that have been reported in the previous works to study the compressibility of composites. Moreover, the compaction of the composite powder mixture has been investigated by some theoretical and analytical models [91,92]. Hesabi et al. have investigated the consolidation behavior of aluminum powder in the presence of $5 \mathrm{vol} \%$ nano alumina during the uniaxial compaction [93]. They have shown that the load portioning effect of nanoparticles reduces the densification rate of the composite powder mixture, leading to a lower density with respect to the pure aluminum. It is also found that mechanical milling remarkably affects the compaction behavior of both pure aluminum and the composite powder mixture. As a matter of fact, the morphological changes of particles during the milling process enhance the contribution of particle rearrangement in densification, whereas the plastic deformation mechanism is noticeably retarded as a consequence of the work hardening effect. Saboori et al. have studied the effect of graphene nanoplatelets on the compressibility of Al nanocomposites consolidated by unidirectional die compaction [94]. They have evaluated the relative density of Al/GNPs nanocomposites as a function of compaction pressure and graphene content. Their outcomes show that the mechanism of densification at low $(<500 \mathrm{MPa})$ and high $(>700 \mathrm{MPa})$ compaction pressures are particle rearrangement and plastic deformation of particles (Figure 6), respectively. Furthermore, their compressibility studies, which have been carried out by using the Ge, Heckel and Panelli and Ambrozio Filho compaction equations, indicate that the plastic deformation capacity of aluminum particles is reduced as the graphene content increases as a consequence of the load partitioning effect.

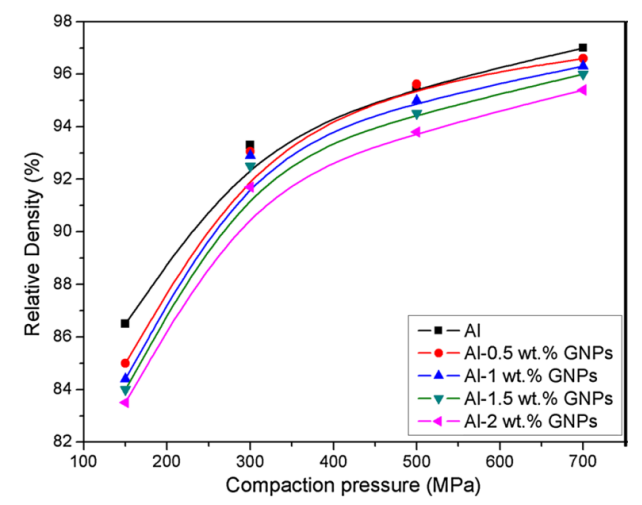

Figure 6. Compaction behavior of Al- $x$ wt. \% GNP $(x=0,0.5,1.0,1.5,2.0)$ nanocomposites, reproduced from [94], with permission from Springer Nature, 2018. 
Apart from the effect of GNPs on the compressibility of MMNCs, it is found that owing to the high aspect ratio of graphene nanoplatelets, the preferred orientation of GNPs could take place during the consolidation by uniaxial compaction (mainly perpendicular to the pressing direction). Fan et al. have evaluated the effect of graphene content on the microstructure and properties of copper matrix composite prepared by the molecular level mixing process followed by spark plasma sintering [17]. They have found two different types of graphene distributions within the matrix; a random distribution at low graphene content $(<0.8 \mathrm{vol} \%)$ and a preferred orientation of graphene perpendicular to the compaction direction at high graphene content ( $>2 \mathrm{vol} \%)$. It is reported that the strengthening effects of graphene were firstly increased and thereafter decreased by increasing the graphene content. Similarly, Saboori et al. have found that by increasing the GNP content (>2 vol \%), some agglomerates started to form, and this agglomerates adversely affects the final characteristics of the nanocomposite (Figure 7) [69]. In addition, it is reported that during the consolidation of composite powder, the GNPs oriented preferentially (perpendicular to the force direction), consequently leading to the anisotropic properties of the composite. Rashad et al. have studied the effect of graphene nanoplatelets on the strength and ductility of a Mg-Al alloy produced by the semi-powder metallurgy method [95]. In this work, the wet mixing method was used as the dispersion method, and the final specimens have been produced by the combination of conventional powder metallurgy and hot extrusion techniques. Their microstructural investigations have shown that GNPs were dispersed homogeneously into the magnesium matrix, resulting in the improvement mechanical properties (Figure 8). The graphene orientation cannot only be revealed from SEM images, but is also revealed in the anisotropic properties of the fabricated composites. Indeed, this preferred orientation of graphene can be a great advantage for some specific applications, but in most applications, isotropic material behavior is essential.

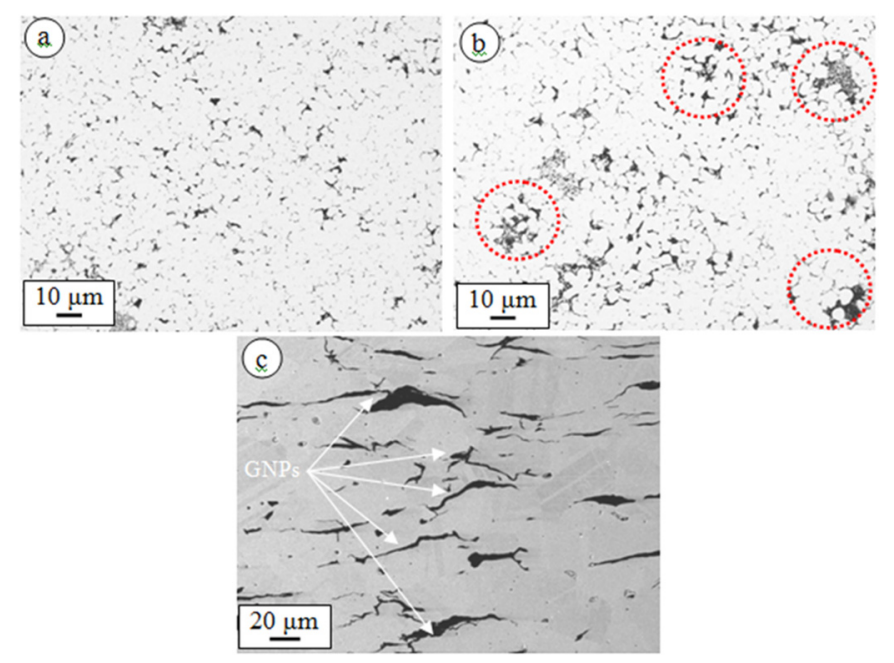

Figure 7. Scanning electron microscopy images of sintered: (a) Cu-4 vol \% GNPs; (b) Cu-8 vol \% GNPs parallel to the consolidation direction; and (c) $\mathrm{Cu}-8 \mathrm{vol} \%$ GNPs perpendicular to the consolidation direction [96]. 

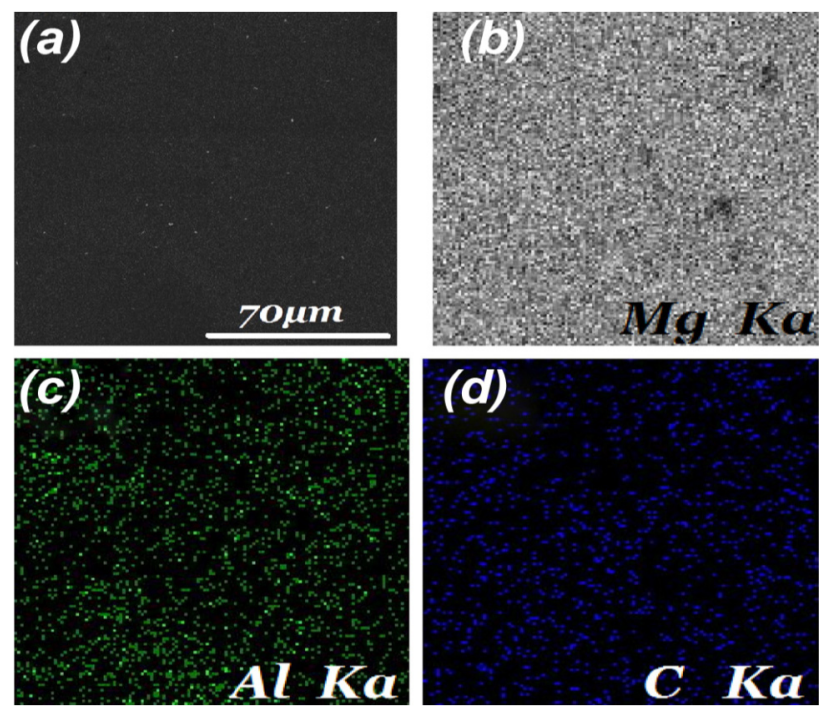

Figure 8. X-ray maps of: (a) Mg-1.0 wt. \% Al-0.018 wt. \% GNP composite; (b) Mg; (c) Al; (d) carbon, reproduced from [95], with permission from Elsevier, 2015.

\subsection{Reactivity and Interface Design (Fourth and Fifth Challenge)}

One of the most important issues, when changing from micron size reinforcement to nano-sized reinforcement, is the proper design of the matrix/reinforcement interface. However, a considerable amount of literature has reported that the reaction between the reinforcement and metallic matrices is an important issue that should be considered in the fabrication of MMNCs reinforced with GNPs. Different theories exist in the literature regarding the reaction between $\mathrm{Al}$ and carbon-based reinforcement resulting in $\mathrm{Al}_{4} \mathrm{C}_{3}$ formation. Saboori et al. have studied the possible $\mathrm{Al}_{4} \mathrm{C}_{3}$ formation, in the $\mathrm{Al} / \mathrm{GNP}$ system and set the framework to avoid this undesirable reaction [97]. In their research, the consolidated powders were heated from $30^{\circ} \mathrm{C}-700{ }^{\circ} \mathrm{C}$ in an alumina crucible with a heating rate of $20^{\circ} \mathrm{C} / \mathrm{min}$. Figure 9 shows the differential scanning calorimetry curves of $\mathrm{Al}$ and $\mathrm{Al}-2.0 \mathrm{wt}$. \% GNPs up to $700{ }^{\circ} \mathrm{C}$. In the DSC curves, it is revealed that in both pure $\mathrm{Al}$ and $\mathrm{Al} / \mathrm{GNP}$ nanocomposites, there is an endothermic peak at the melting point of aluminum $\left(\sim 660^{\circ} \mathrm{C}\right)$. However, in the $\mathrm{Al} / \mathrm{GNP}$ nanocomposite curve, it seems that the endothermic peak could overlap the exothermic peak. To verify this theory, the peak enthalpy has been measured, and it resulted in being lower than pure Al. The fact that an exothermic phenomenon occurs simultaneously with an endothermic one related to the melting of $\mathrm{Al}$, it shows that the reaction between aluminum and graphene has taken place and resulted in the formation of $\mathrm{Al}_{4} \mathrm{C}_{3}$ [97]. This formation of $\mathrm{Al}_{4} \mathrm{C}_{3}$ during the heating has been proven by the $\mathrm{X}$-ray diffraction patterns. It is found from the thermodynamic aspect that, as soon as aluminum melts, it reacts with graphene, and $\mathrm{Al}_{4} \mathrm{C}_{3}$ forms as a consequence. 

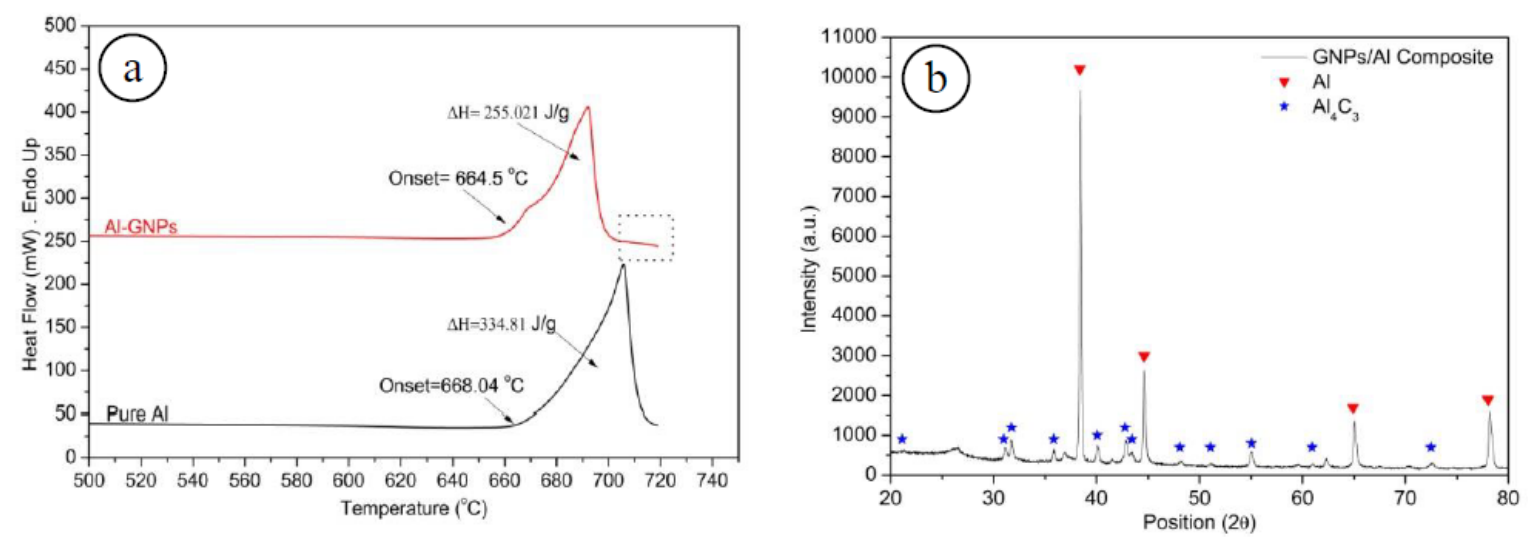

Figure 9. (a) Differential scanning calorimetry curves of pure $\mathrm{Al}$ and $\mathrm{Al}-2.0$ wt. \% GNPs; (b) X-ray diffraction pattern of Al-2.0 wt. \% GNPs after the thermal analysis, reproduced from [97], with permission from from Springer Nature, 2017.

Aluminum carbide is the most energetically favorable stoichiometry of $\mathrm{Al}_{4} \mathrm{C}_{3}$ to form at the temperatures of interest in the fabrication of aluminum matrix nanocomposites reinforced with graphene [98]. This carbide formation has been reported also in MMCs reinforced by carbon fibers and graphene, and it is shown that this $\mathrm{Al}_{4} \mathrm{C}_{3}$ deteriorates the final mechanical strength of composites $[68,94]$. It is shown that the highly stable defect-free graphitic planes of the CNTs or graphene do not react with aluminum to form $\mathrm{Al}_{4} \mathrm{C}_{3}$ even at elevated temperatures when the aluminum is liquid [99]. Defects in the graphitic planes of graphene, tube ends and amorphous carbon coating at temperatures below the aluminum melting point are the favorable places for $\mathrm{Al}_{4} \mathrm{C}_{3}$ formation $[68,99]$. Due to the effect of several parameters on the $\mathrm{Al}_{4} \mathrm{C}_{3}$ formation in the $\mathrm{Al} / \mathrm{C}$ system, some authors have reported this formation [99-102], while others have not detected it [103-105]. Bartolucci et al. have studied the reactivity in the Al/GNPs system [68]. In their research, the materials have been hot isostatic presses (HIPed) at $\sim 375{ }^{\circ} \mathrm{C}$ for $20 \mathrm{~min}$ and then preheated at $\sim 550{ }^{\circ} \mathrm{C}$ for $4 \mathrm{~h}$ before the extrusion process. A temperature increment can be anticipated during extrusion as a consequence of generated heat due to deformation and friction during the process, but it is likely to be lower than $\sim 50{ }^{\circ} \mathrm{C}$ and only happens for a short period. They have found that the presence of $\mathrm{Al}_{4} \mathrm{C}_{3}$ in the composite was detected in the composites that had been processed at temperatures above $500{ }^{\circ} \mathrm{C}$. Deng et al. did not detect $\mathrm{Al}_{4} \mathrm{C}_{3}$ in the composite after the extrusion at $\sim 460{ }^{\circ} \mathrm{C}$, but they have revealed it in differential scanning calorimetry (DSC) tests above $\sim 672{ }^{\circ} \mathrm{C}$ [102]. Kwon et al. have evaluated the carbide formation in specimens heat treated at $\sim 500{ }^{\circ} \mathrm{C}$ for $2 \mathrm{~h}$ followed by the SPS process at temperatures between 480 and $600{ }^{\circ} \mathrm{C}$ [106]. Their results confirm the formation of $\mathrm{Al}_{4} \mathrm{C}_{3}$ even at these low temperatures. Ci et al. report the formation of aluminum carbide in CVD MWNT sputtered Al composites after annealing at $500{ }^{\circ} \mathrm{C}$ and above [99]. Their XRD analysis did not show any evidence of $\mathrm{Al}_{4} \mathrm{C}_{3}$ formation in the samples annealed at $400{ }^{\circ} \mathrm{C}$. Moreover, it is found that thermal reduction of $\mathrm{GO}$, which is one of the techniques of graphene production, results in the production of graphene with a wrinkled morphology and defects on the graphitic basal plane $[107,108]$. This can be observed in the transmission electron microscopy (TEM) micrograph in Figure 10a. The abundance of defect sites is also verified by Raman spectroscopy. Raman analysis (Figure 10b) of the graphene powder shows an intense $\mathrm{D}$ band and a significant broadening of both the $\mathrm{D}$ and $\mathrm{G}$ bands, indicating a high degree of disorder. This high density of defects is an artefact of the oxidation of graphite and the thermal shock technique that was used to exfoliate graphite oxide to GNPs. The abundant amount of prism planes at the GNP edges could also become the favorable sites of reaction. This could lead to significant amounts of $\mathrm{Al}_{4} \mathrm{C}_{3}$ when compared to the total volume fraction of graphene since the graphene sheets are only on the order of a few atomic layers thick. 

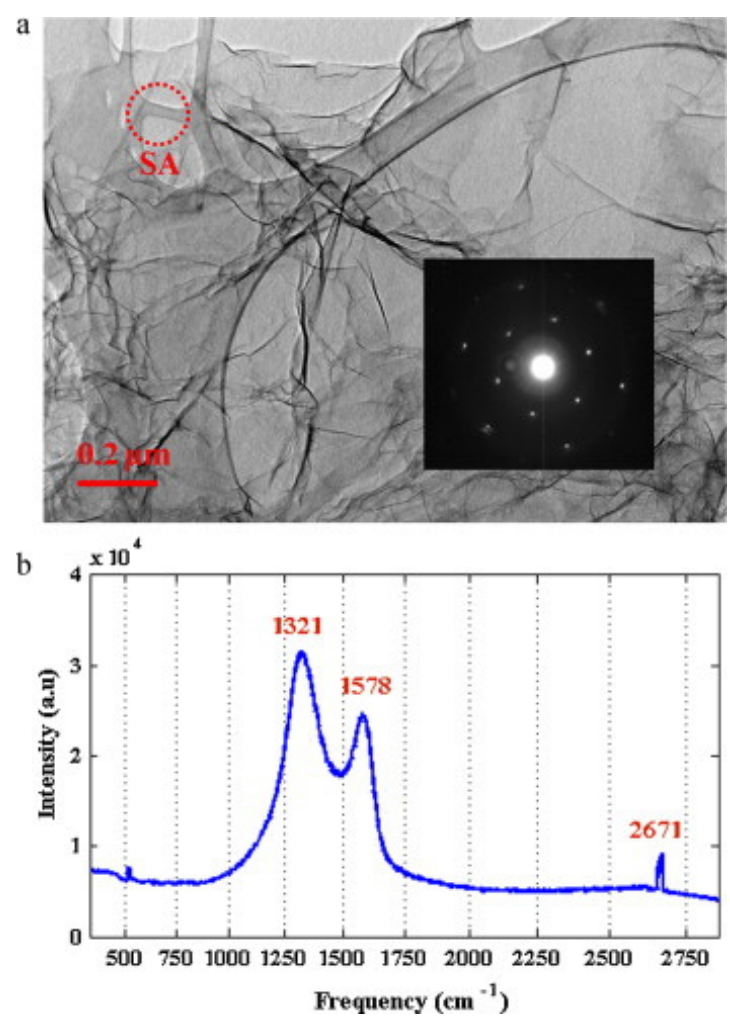

Figure 10. (a) Transmission electron microscopy (TEM) image of GNP with the wrinkled morphology; (b) Raman analysis of as-received GNPs, SAD (selected area diffraction), reproduced from [68], with permission from Elsevier, 2011.

In another research work, Rashad et al. have evaluated the phase composition of $\mathrm{Mg} / \mathrm{GNP}$ nanocomposites after sintering at $630^{\circ} \mathrm{C}$ for $110 \mathrm{~min}$ followed by hot extrusion at $350{ }^{\circ} \mathrm{C}$ [15]. It is reported that the fabrication of Mg/GNPs at these temperatures does not result in the reaction between the matrix and the reinforcement. The X-ray diffraction (XRD) pattern of GNPs, monolithic magnesium and Mg- $x \mathrm{Al}-0.18 \mathrm{GNP}(x=0.5,1.0,1.5)$ nanocomposites produced in the aforementioned research are shown in Figure 11.

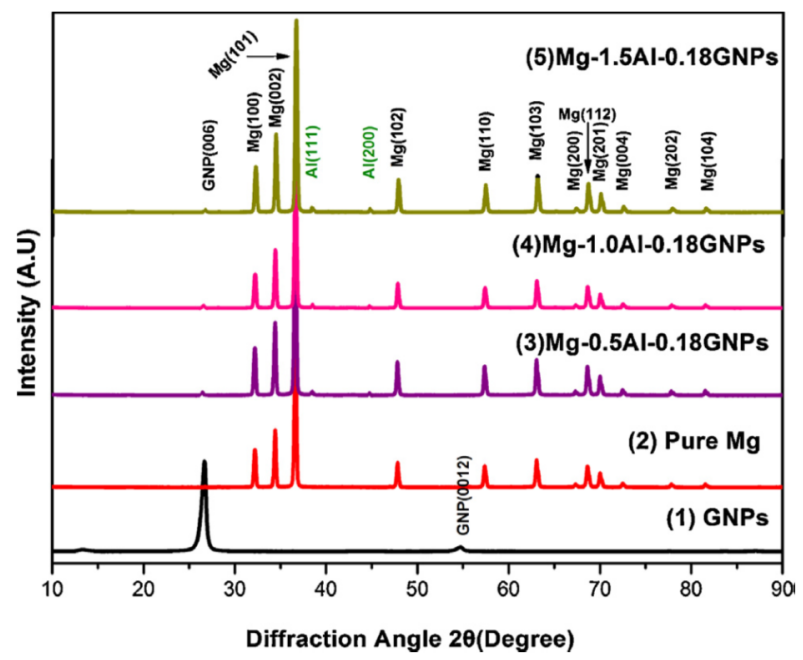

Figure 11. X-ray diffraction patterns of GNP, pure $\mathrm{Mg}$ and $\mathrm{Mg}-x \mathrm{Al}-0.18 \mathrm{GNP}$ composites $(x=0.5 ; 1.0$; 1.5), reproduced from [95], with permission from Elsevier, 2015. 
Another critical challenge in MMNCs reinforced with GNPs is the appropriate design of the interface between the metal matrix and GNPs. In particular, in this kind of nanocomposite, due to the significantly increased surface/volume ratio, the interface area increases noticeably, and thus, its design is vital. This interface design becomes very important especially when the thermal and mechanical characteristics of GNPs are of interest and a perfect mechanical bond and low thermal resistance are required. In general, the mechanical and thermal interface can be improved by surface modification such as roughening and using an interlayer by either deposition of an interlayer or addition of alloying elements to facilitate dome interfacial reactions and create a reaction bonding. However, as discussed earlier, in some cases like Al/GNP nanocomposites, this interfacial reaction should be considered and controlled.

\section{Properties of MMNCs Reinforced by GNPs}

\subsection{Density and Vickers Hardness}

Metal matrix nanocomposites reinforced by nanoparticles could have attracted more attention in recent years because of their promising properties with respect to unreinforced matrices. The nano-scale particles that are used these days in the MMNCs as reinforcement play a key role in the improvement of the properties of composites. Hence, to understand the relevant mechanism of improvement and predict the effect of reinforcement on the matrix for the sake of materials' design, several theoretical and experimental approaches have been proposed, which are described further.

The ratio between total mass and the total volume is known as the density of a composite material. By using the rule of mixture, it would be possible to calculate the density variations of the composite as a function of reinforcement content regardless of reinforcement distribution. Thus, the following equation can be used to calculate the density of a composite consisting of two different constituents [109]:

$$
\rho_{c}=\rho_{p} V_{p}+\rho_{m} V_{m}
$$

where $\rho$ is the density, $V$ is the volume fraction and the subscripts " $c$ ", " $p$ " and " $m$ " denote the composite, particle and matrix, respectively. Table 4 presents the effect of GNP addition on the density of different metal matrix nanocomposites.

Table 4. Theoretical and sintered density of MMNCs reinforced with graphene nanoplatelets.

\begin{tabular}{|c|c|c|c|c|c|}
\hline Matrix & $\begin{array}{l}\text { Graphene Content } \\
\text { (wt. \%) }\end{array}$ & Fabrication Techniques & $\begin{array}{l}\text { Theoretical Density } \\
\left(\mathrm{g} / \mathrm{cm}^{3}\right)\end{array}$ & $\begin{array}{c}\text { Sintered Density } \\
\left(\mathrm{g} / \mathrm{cm}^{3}\right)\end{array}$ & Ref. \\
\hline \multirow{2}{*}{$\mathrm{Mg}$} & 0 & Semi-PM & 1.740 & 1.738 & [95] \\
\hline & 0.18 & Semi-PM & 1.743 & 1.733 & [95] \\
\hline \multirow{3}{*}{$\mathrm{Al}$} & 0 & Conventional PM & 2.700 & 2.646 & {$[110]$} \\
\hline & 0.5 & Conventional PM & 2.695 & 2.628 & [110] \\
\hline & 1.0 & Conventional PM & 2.690 & 2.556 & [110] \\
\hline \multirow{3}{*}{$\mathrm{Al}$} & 0 & Hot rolling & 2.700 & 2.557 & [70] \\
\hline & 0.5 & Hot rolling & 2.695 & 2.526 & [70] \\
\hline & 1.0 & Hot rolling & 2.690 & 2.441 & {$[70]$} \\
\hline \multirow{3}{*}{$\mathrm{Cu}$} & 0 & Conventional PM & 8.961 & 8.781 & {$[111]$} \\
\hline & 1.0 & Conventional PM & 8.661 & 8.532 & [111] \\
\hline & 2.0 & Conventional PM & 8.391 & 8.143 & [111] \\
\hline \multirow{3}{*}{$\mathrm{Cu}$} & 0 & Conventional PM + Repressed + annealed & 8.960 & 8.821 & [8] \\
\hline & 1.0 & Conventional PM+ Repressed + annealed & 8.660 & 8.562 & [8] \\
\hline & 2.0 & Conventional PM + Repressed + annealed & 8.390 & 8.231 & [8] \\
\hline \multirow{3}{*}{$\mathrm{Cu}$} & 0 & Conventional PM + HIP & 8.960 & 8.951 & [8] \\
\hline & 1.0 & Conventional PM + HIP & 8.660 & 8.652 & [8] \\
\hline & 2.0 & Conventional PM + HIP & 8.390 & 8.371 & [8] \\
\hline \multirow{4}{*}{$\mathrm{Al}$} & 0 & Hot extrusion & 2.700 & 2.699 & [79] \\
\hline & 0.25 & Hot extrusion & 2.699 & 2.698 & [79] \\
\hline & 0.5 & Hot extrusion & 2.697 & 2.696 & [79] \\
\hline & 1.0 & Hot extrusion & 2.694 & 2.691 & [79] \\
\hline
\end{tabular}


Two common trends are present in all the reported densities: (i) reduction of the sintered density of the nanocomposites with respect to the monolithic metal or alloy; (ii) porosity increment by increasing the graphene content. It has been reported that the reduction in the theoretical density of nanocomposites as a function of GNPs is because of the low density of graphene $\left(2.1 \mathrm{~g} / \mathrm{cm}^{3}\right)[8,79]$.

Saboori et al. have studied the effect of post-processing on the density of the $\mathrm{Cu} / \mathrm{GNP}$ nanocomposites [8]. The most interesting finding was that by increasing the graphene content apart from the location of GNPs at the grain boundaries, the graphene nanoplatelets tend to form agglomerates. Moreover, it should be noted that a weak interfacial bonding between the graphene and copper after pressureless sintering results in a low density. This interfacial bonding is improved as a consequence of porosity eliminations by using some post-processing techniques like the repressing and annealing process, as well as hot isostatic pressing (Figure 12).

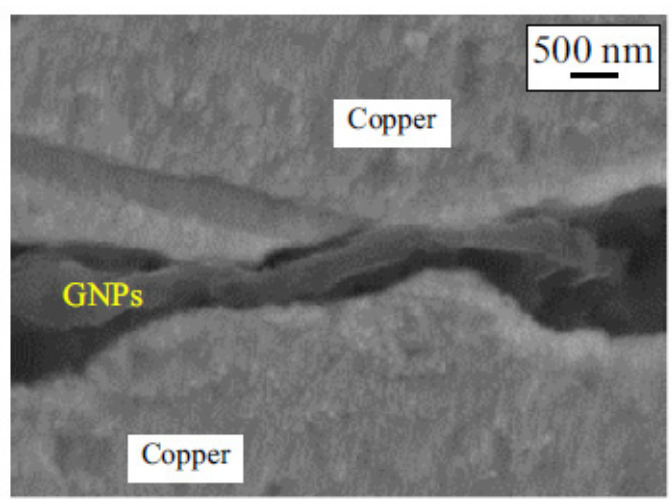

(a)

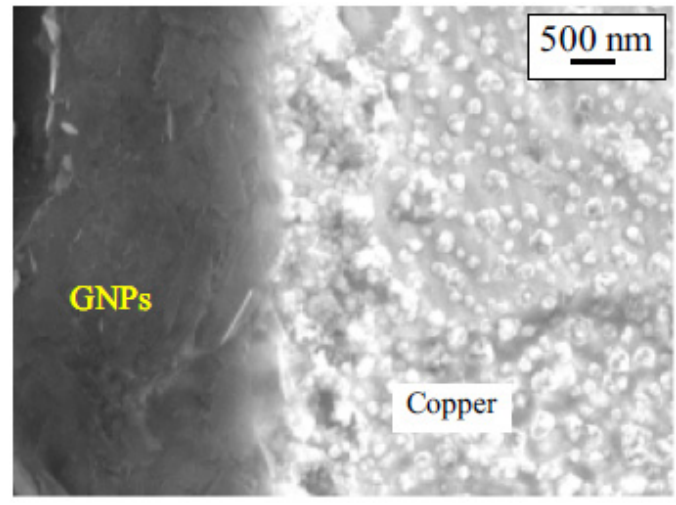

(b)

Figure 12. Field emission scanning electron microscopy (FESEM) images of the Cu/GNPs interfacial bonding for the: (a) as-sintered; (b) as-sintered followed by the HIPing process, reproduced from [8], with permission from Springer Nature, 2018.

The Vickers hardness of pure metals and metal/GNPs is presented in Table 5. As can be seen, in general, the addition of reinforcement particles (GNPs) to monolithic metals increases the hardness. Up to now, several studies have investigated this increment, and it has been suggested that the increase of hardness of nanocomposites can be attributed to the uniform distribution of the strong reinforcement and high durability of the metal matrix versus the deformation during the loading [79,94,96,112].

In general, it is reported that reinforcement in metal matrix nanocomposites can improve the mechanical strength of the matrix by: (i) the load partitioning effect; (ii) hindering the plastic deformation of the matrix [112,113]. Moreover, two vital factors to specify the strengthening efficiency of reinforcing the material, other than intrinsic mechanical characteristics and volume fraction, are (I) the amount of load that can be effectively transferred from the matrix to the reinforcement and (II) the amount of stress distribution that can be changed by the reinforcement. The effect of these two important factors implies that the matrix/reinforcement interfacial bonding, morphology/surface area and dispersion of the reinforcement is very critical [114,115].

Because of the complex behavior of graphene within the metal matrices either as a consequence of the production process or its nature, different research has attributed its strengthening effect on different MMNCs to various reasons. For instance, Rashad et al. have studied the effect of GNPs on the mechanical strength of Mg-1Al-1Sn alloy [1]. In their work, the strengthening effect of graphene is attributed to dislocation generation as a result of a significant mismatch between the coefficient of thermal expansion and the elastic modulus. Moreover, it was reported that owing to the presence of strong interfacial bonding between the graphene and matrix, the load transfer mechanism plays a great role in the strengthening of the composite. In another study, Saboori et al. investigated the effect of graphene content and post-processing techniques on the interfacial bonding and hardness of 
$\mathrm{Cu} / \mathrm{GNP}$ nanocomposites [8]. The strengthening effect of graphene in this work is correlated with the Hall-Petch strengthening effect, which is a result of grain refinement. Furthermore, it is revealed that by using the hot isostatic pressing as a post-processing technique, the hardness of both monolithic copper and $\mathrm{Cu} / \mathrm{GNPs}$ nanocomposites is increased by more than $25 \%$. In fact, this improvement is correlated with the porosity elimination during the HIPing process, which resulted in the formation of stronger $\mathrm{Cu} / \mathrm{GNP}$ interfacial bonding.

Table 5. Vickers hardness of different metals and their metal matrix nanocomposites reinforced with GNPs.

\begin{tabular}{|c|c|c|c|c|}
\hline Matrix & $\begin{array}{c}\text { Graphene Content } \\
\text { (wt. \%) }\end{array}$ & Fabrication Techniques & $\begin{array}{c}\text { Vickers Hardness } \\
\text { (HV) }\end{array}$ & Ref. \\
\hline \multirow{4}{*}{$\mathrm{Al}$} & 0 & Hot extrusion & $76 \pm 4.0$ & [79] \\
\hline & 0.25 & Hot extrusion & $80 \pm 5.0$ & [79] \\
\hline & 0.5 & Hot extrusion & $85 \pm 4.0$ & [79] \\
\hline & 1.0 & Hot extrusion & $90 \pm 4.0$ & [79] \\
\hline \multirow{3}{*}{$\mathrm{Al}$} & 0 & Conventional PM & $44 \pm 2.1$ & [110] \\
\hline & 0.5 & Conventional PM & $51 \pm 1.4$ & [110] \\
\hline & 1.0 & Conventional PM & $57 \pm 4.2$ & [110] \\
\hline \multirow{3}{*}{$\mathrm{Al}$} & 0 & Hot rolling & $42 \pm 1.1$ & [70] \\
\hline & 0.5 & Hot rolling & $43 \pm 1.5$ & [70] \\
\hline & 1.0 & Hot rolling & $42 \pm 2.3$ & [70] \\
\hline \multirow{3}{*}{$\mathrm{Cu}$} & 0 & Conventional PM & $42.3 \pm 2.1$ & [111] \\
\hline & 1.0 & Conventional PM & $45.1 \pm 3.2$ & [111] \\
\hline & 2.0 & Conventional PM & $48.6 \pm 5.0$ & [111] \\
\hline \multirow{3}{*}{$\mathrm{Cu}$} & 0 & Conventional PM + Repressed + annealed & $45.2 \pm 1.5$ & [8] \\
\hline & 1.0 & Conventional PM + Repressed + annealed & $51.6 \pm 2.2$ & [8] \\
\hline & 2.0 & Conventional PM + Repressed + annealed & $55.8 \pm 3.6$ & {$[8]$} \\
\hline \multirow{3}{*}{$\mathrm{Cu}$} & 0 & Conventional PM + HIP & $50.4 \pm 0.9$ & [8] \\
\hline & 1.0 & Conventional PM + HIP & $57.5 \pm 1.6$ & [8] \\
\hline & 2.0 & Conventional PM + HIP & $62.3 \pm 1.2$ & [8] \\
\hline \multirow{2}{*}{$\mathrm{Mg}$} & 0 & Semi-PM & $41 \pm 4.0$ & [95] \\
\hline & 0.18 & Semi-PM & $55 \pm 2.0$ & [95] \\
\hline
\end{tabular}

\subsection{Electrical Conductivity}

In recent years, there has been an increasing amount of literature on the effect of GNPs on the electrical conductivity of graphene $[8,69]$. For instance, Figure 13 shows the electrical conductivity of pure $\mathrm{Cu}$ and its composites after sintering followed by HIPing [8]. It is reported that the electrical conductivity measurements have been carried out perpendicular to the compacting direction. From the graph, it is clear that the electrical conductivity of pure $\mathrm{Cu}$ and copper composites is higher in the case of HIPed samples regarding the sintered ones. This discrepancy can be attributed to the higher density, lower porosity and the existence of stronger interfacial bonding between $\mathrm{Cu}$ and graphene after HIPing. In fact, the high amount of the isolating elements such as voids and poor interfaces can prevent the continuity of electron pathways in the matrix [30,116]. Apart from the effect of post-processing, it can be seen that by increasing the GNP content, the electrical conductivity decreased from $78 \%$ IACS (International Annealed Copper Standard) to 67\% IACS. 


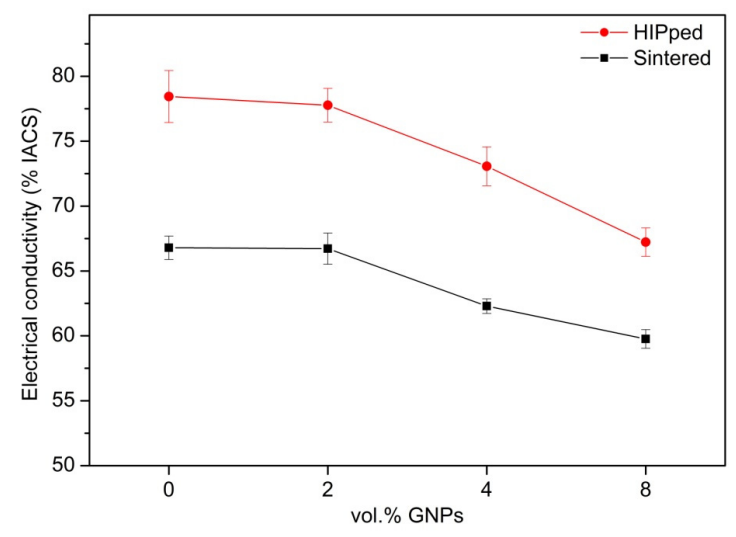

Figure 13. The electrical conductivity of pure $\mathrm{Cu}$ and $\mathrm{Cu}$-GNPs nanocomposites vs. vol \% of GNPs for as-sintered and hot isostatic presses (HIPed) specimens, reproduced from [8], with permission from Springer Nature, 2018. IACS, International Annealed Copper Standard.

It is suggested that the reduction in the electrical conductivity with increasing of the GNP content could be due to different reasons such as decreasing the mean free path of electrons as a result of grain refinement and higher dislocation density at higher GNP content [17]; porosities that can interrupt the electrons motions [117]. As is shown, the negative variation of electrical conductivity was less than $20 \%$ in the case of $8.0 \mathrm{vol} \%$ graphene addition, whereas the addition of graphene up to $2.0 \mathrm{vol} \%$ did not change the electrical conductivity of copper. This implies that the addition of a low content of graphene will not deteriorate the electrical conductivity of copper composite remarkably. However, this effect has been reported in the literature, as shown in Table 6.

Table 6. A summary of the electrical conductivity of copper composites reinforced with different types and vol \% of reinforcements. SPS, spark plasma sintering.

\begin{tabular}{ccccc}
\hline Reinforcement & Content & $\begin{array}{c}\text { Electrical Conductivity } \\
\text { (\% IACS) }\end{array}$ & Fabrication Method & Ref. \\
\hline CNTs & $0.5 \mathrm{vol} \%$ & 91.2 & SPS + wire drawing & {$[118]$} \\
GNPs & $0.6 \mathrm{vol} \%$ & 88 & $\begin{array}{c}\text { Molecular level mixing + SPS } \\
\text { Cu coating of graphene + sintering }\end{array}$ & {$[119,120]$} \\
Graphite & $8.0 \mathrm{wt} \%$ & 55 & Roll bonding & {$[121]$} \\
Graphite & $0.1 \mathrm{vol} \%$ & 90 & Sintering + Forging & {$[122]$} \\
- & - & 52.3 & Sintering + Forging & {$[8]$} \\
SWCNTs & $5.0 \mathrm{vol} \%$ & 44.5 & Sintering + HIPing & {$[8]$} \\
- & - & 78 & Sintering + HIPing & {$[8]$} \\
GNPs & $2.0 \mathrm{vol} \%$ & 72.5 & Sintering + HIPing & {$[8]$} \\
GNPs & $4.0 \mathrm{vol} \%$ & 67.5 & Sintering + HIPing & \\
GNPs & $8.0 \mathrm{vol} \%$ & & & \\
\hline
\end{tabular}

Saboori et al. have found that, apart from the effect of graphene, the electrical conductivity of pure copper after hot isostatic pressing was only $\sim 78 \%$ IACS. After that, they have explained that the electrical conductivity of reference copper is the electrical conductivity of the oxygen free and annealed copper with very high purity, while in their research, the starting copper contained a few impurities that significantly affected the electrical conductivities. As a matter of fact, this impurity in the matrix disturbs the conductance by either decreasing the mean free path of electrons or increasing the scattering surface for conduction electrons [123]. Nadkarani et al. [124] reported a similar value for electrical conductivity, 78\% IACS, for partially-oxidized copper containing $0.2 \mathrm{vol} \% \mathrm{Al}_{2} \mathrm{O}_{3}$.

\subsection{Tribological Performance}

Within the relative movement of two surfaces, various kinds of wear mechanisms such as adherence wear, abrasive wear, and so on, may take place. Therefore, the tribological behavior 
and wear resistance of metallic materials, in particular aluminum and aluminum alloys, are key features that should be considered in the design of new materials. One of the interesting methods to reduce the friction and improve the wear resistance of the material under wear conditions is using GNPs as reinforcement within the MMNCs $[7,9,125]$. Tanabande-Khorshid et al. have studied the role of GNPs in the tribological performance of aluminum matrix nanocomposites [7]. In their research, the pin-on-disk method has been chosen to study the wear behavior of pure aluminum and its nanocomposites reinforced with GNPs. Their outcomes have shown that although the wear rate of AMNCs is increased with increasing normal load, the coefficient of friction (COF) of Al- $1 \mathrm{wt}$. \% GNPs reduced by increasing normal load. Their surface analysis shows that the AMNCs reinforced with GNPs have superior wear resistance with respect to those that are unreinforced.

\section{Conclusions}

As discussed in the Introduction, over several years, several studies have established that GNP-reinforced MMNCs have great potential in different sectors. However, several lines of evidence reported that the fabrication of these interesting MMNCs faces several challenges. This review is carried out to study some of the technical challenges that are faced during the fabrication of MMNCs reinforced with GNPs in order to take advantage of the superior features of reinforcement within the metallic matrix. The main technical challenges are: (I) reinforcement selection; (II) dispersion of reinforcement within the matrix; (III) reactivity between the reinforcement and matrix; (IV) interfacial bonding; (V) preferred orientation of reinforcement. In particular, some of these difficulties can be attributed to the nature of the materials involved, while some of them are related to the preparation technique. It seems that this latter one can often be solved by changing the production process or by using post-processing techniques. More challenging, instead, are the problems related to the composition of matrix and reinforcement, their reactivity and the dispersion of particles, in particular if nano-sized. These topics still bring a significant challenge to the materials scientists, and it would be worth mentioning that the fabrication of MMNCs with a uniform dispersion of graphene nanoplatelets, strong interfacial bonding, without detrimental reactions and improved isotropic properties is still a puzzling issue.

Author Contributions: In this review, Abdollah Saboori, Seyed Kiomars Moheimani and Mehran Dadkhah searched the literature to find the proper research and published works and wrote the paper. Abdollah Saboori and Matteo Pavese defined the structure of the paper and challenges that should be discussed in the paper. Claudio Badini and Paolo Fino reviewed the paper.

Conflicts of Interest: The authors declare no conflict of interest.

\section{References}

1. Rashad, M.; Pan, F.; Asif, M.; Tang, A. Powder metallurgy of Mg-1\%Al-1\%Sn alloy reinforced with low content of graphene nanoplatelets (GNPs). J. Ind. Eng. Chem. 2014, 20, 4250-4255. [CrossRef]

2. Wang, X.; Li, J.; Wang, Y. Improved high temperature strength of copper-graphene composite material. Mater. Lett. 2016, 181, 309-312. [CrossRef]

3. Wang, J.; Li, Z.; Fan, G.; Pan, H.; Zhang, D. Reinforcement with graphene nanosheets in aluminum matrix composites. Sci. Mater. 2012, 66, 594-597. [CrossRef]

4. Jeon, C.-H.; Jeong, Y.-H.; Seo, J.-J.; Tien, H.N.; Hong, S.-T.; Yum, Y.-J.; Hur, S.-H.; Lee, K.-J. Material properties of graphene/aluminum metal matrix composites fabricated by friction stir processing. Int. J. Precis. Eng. Manuf. 2014, 15, 1235-1239. [CrossRef]

5. Perez-Bustamante, R.; Bolanos-Morales, D.; Bonilla-Maetinez, J.; Estrada-Guel, I. Microstructural and hardness behavior of graphene-nanoplatelets/aluminum composites synthesized by mechanical alloying. J. Alloy. Compd. 2014, 615, S578-S582. [CrossRef]

6. Saboori, A.; Padovano, E.; Pavese, M.; Badini, C. Novel Magnesium Elektron21-AlN Nanocomposites Produced by Ultrasound-Assisted Casting; Microstructure, Thermal and Electrical Conductivity. Materials 2018, 11, 27. [CrossRef] [PubMed] 
7. Tabandeh-Khorshid, M.; Omrani, E.; Menezes, P.L.; Rohatgi, P.K. Tribological performance of self-lubricating aluminum matrix nanocomposites: Role of graphene nanoplatelets. Eng. Sci. Technol. Int. J. 2016, 19, 463-469. [CrossRef]

8. Saboori, A.; Pavese, M.; Badini, C.; Fino, P. A Novel Approach to Enhance the Mechanical Strength and Electrical and Thermal Conductivity of Cu-GNP Nanocomposites. Metall. Mater. Trans. A Phys. Metall. Mater. Sci. 2018, 49. [CrossRef]

9. Moghadam, A.D.; Omrani, E.; Menezes, P.L.; Rohatgi, P.K. Mechanical and tribological properties of self-lubricating metal matrix nanocomposites reinforced by carbon nanotubes (CNTs) and graphene-A review. Compos. Part B Eng. 2015, 77, 402-420. [CrossRef]

10. Saboori, A.; Padovano, E.; Pavese, M.; Dieringa, H.; Badini, C. Effect of Solution Treatment on Precipitation Behaviors, Age Hardening Response and Creep Properties of Elektron21 Alloy Reinforced by AlN Nanoparticles. Materials 2017, 10, 1380. [CrossRef] [PubMed]

11. Neubauer, E.; Kitzmantel, M.; Hulman, M.; Angerer, P. Potential and challenges of metal-matrix-composites reinforced with carbon nanofibers and carbon nanotubes. Compos. Sci. Technol. 2010, 70, 2228-2236. [CrossRef]

12. Zhang, H.; Xu, C.; Xiao, W.; Ameyama, K.; Ma, C. Enhanced mechanical properties of Al5083 alloy with graphene nanoplates prepared by ball milling and hot extrusion. Mater. Sci. Eng. A 2016, 658, 8-15. [CrossRef]

13. Dieringa, H. Properties of magnesium alloys reinforced with nanoparticles and carbon nanotubes: A review. J. Mater. Sci. 2011, 46, 289-306. [CrossRef]

14. Ben-hamu, G.; Eliezer, D.; Shin, K.S.; Cohen, S. The relation between microstructure and corrosion behavior of Mg-Y-RE-Zr alloys. J. Alloy. Compd. 2007, 431, 269-276. [CrossRef]

15. Chen, Y.; Zhang, X.; Liu, E.; He, C.; Han, Y.; Li, Q.; Nash, P.; Zhao, N. Fabrication of three-dimensional graphene/Cu composite by in-situ CVD and its strengthening mechanism. J. Alloy. Compd. 2016, 688, 69-76. [CrossRef]

16. Yolshina, L.A.; Muradymov, R.V.; Korsun, I.V.; Yakovlev, G.A.; Smirnov, S.V. Novel aluminum-graphene and aluminum-graphite metallic composite materials: Synthesis and properties. J. Alloy. Compd. 2016, 663, 449-459. [CrossRef]

17. Chen, F.; Ying, J.; Wang, Y.; Du, S.; Liu, Z.; Huang, Q. Effects of graphene content on the microstructure and properties of copper matrix composites. Carbon 2016, 96, 836-842. [CrossRef]

18. Yue, H.; Yao, L.; Gao, X.; Zhang, S.; Guo, E.; Zhang, H.; Lin, X.; Wang, B. Effect of ball-milling and graphene contents on the mechanical properties and fracture mechanisms of graphene nanosheets reinforced copper matrix composites. J. Alloy. Compd. 2017, 691, 755-762. [CrossRef]

19. Xue, C.; Bai, H.; Tao, P.F.; Wang, J.W.; Jiang, N. Thermal conductivity and mechanical properties of flake graphite/ Al composite with a SiC nano-layer on graphite surface. Mater. Des. 2016, 108, 250-258. [CrossRef]

20. Gao, X.; Yue, H.; Guo, E.; Zhang, H.; Lin, X.; Yao, L.; Wang, B. Preparation and tensile properties of homogeneously dispersed graphene reinforced aluminum matrix composites. Mater. Des. 2016, 94, 54-60. [CrossRef]

21. Tian, W.; Li, S.; Wang, B.; Chen, X.; Liu, J.; Yu, M. Graphene-reinforced aluminum matrix composites prepared by spark plasma sintering. Int. J. Miner. Met. Mater. 2016, 23, 723-729. [CrossRef]

22. Lavagna, L.; Massella, D.; Pavese, M. Preparation of hierarchical material by chemical grafting of carbon nanotubes onto carbon fibers. Diam. Relat. Mater. 2017, 80, 118-124. [CrossRef]

23. Prasad, S.V.; Asthana, R. Aluminum metal-matrix composites for automotive applications: Tribological considerations. Tribol. Lett. 2004, 17, 445-453. [CrossRef]

24. Musfirah, A.H.; Jaharah, A.G. Magnesium and Aluminum Alloys in Automotive Industry. J. Appl. Sci. Res. 2012, 8, 4865-4875.

25. Kulekci, M.K. Magnesium and its alloys applications in automotive industry. Int. J. Adv. Manuf. Technol. 2008, 39, 851-865. [CrossRef]

26. Saboori, A.; Gallo, D.; Biamino, S.; Fino, P.; Lombardi, M. An Overview of Additive Manufacturing of Titanium Components by Directed Energy Deposition: Microstructure and Mechanical Properties. Appl. Sci. 2017, 7, 883. [CrossRef]

27. Hu, H.; Yu, A.; Li, N.; Allison, J.E. Potential Magnesium Alloys for High Temperature Die Cast Automotive Applications: A Review. Mater. Manuf. Process. 2003, 18, 687-717. [CrossRef] 
28. Macke, A.; Schultz, B.F. Metal Matrix Composites Offer the Automotive Industry and Opportunity to Reduce Vehicle Weight, Improve Performance. Adv. Mater. Process. 2012, 170, 19-23.

29. Saboori, A.; Pavese, M.; Badini, C.; Eivani, A.R. Studying the age hardening kinetics of A357 aluminum alloys through the Johnson-Mehl-Avrami theory. Met. Powder Rep. 2017, 72, 420-424. [CrossRef]

30. Rajkumar, K.; Aravindan, S. Tribological behavior of microwave processed copper-nanographite composites. Tribiol. Int. 2013, 57, 282-296. [CrossRef]

31. Metal Matrix Composite. 2013. Available online: https://en.wikipedia.org/wiki/Metal_matrix_composite (accessed on 25 November 2017).

32. Kopeliovich, D. Metal Matrix Composites (Introduction). 2013. Available online: http://www.substech. com/dokuwiki/doku.php?id=metal_matrix_composites_introduction (accessed on 25 November 2017).

33. Casati, R.; Vedani, M. Metal Matrix Composites Reinforced by Nano-Particles-A Review. Metals 2014, 4, 65-83. [CrossRef]

34. Chen, Z.-C.; Takeda, T.; Ikeda, K. Microstructural evolution of reactive-sintered aluminum matrix composites. Compos. Sci. Technol. 2008, 68, 2245-2253. [CrossRef]

35. Kopeliovich, D. Polymer Matrix Composites (Introduction). 2013. Available online: http:/ /www.substech. com/dokuwiki/doku.php?id=polymer_matrix_composites_introduction (accessed on 11 September 2017).

36. Kopeliovich, D. Ceramic Matrix Composites (Introduction). 2013. Available online: http:/ /www.substech. com/dokuwiki/doku.php?id=ceramic_matrix_composites_introduction (accessed on 11 September 2017).

37. Callister, W.D. Materials Science and Engineering-An Introduction; John Wiley \& Sons, Inc.: Hoboken, NJ, USA, 2007; ISBN 9780471736967.

38. Tang, Y.; Liu, L.; Li, W.; Shen, B.; Hu, W. Interface characteristics and mechanical properties of short carbon fibers / Al composites with different coatings. Appl. Surf. Sci. 2009, 255, 4393-4400. [CrossRef]

39. Włodarczyk-Fligier, A.; Dobrzański, L.A.; Kremzer, M.; Adamiak, M. Manufacturing of aluminium matrix composite materials reinforced by $\mathrm{Al}_{2} \mathrm{O}_{3}$ particles. J. Achiev. Mater. Manuf. Eng. 2008, 27, 99-102.

40. Huber, T.; Degischer, H.P.; Lefrance, G.; Schmitt, T. Thermal expansion studies on aluminium-matrix composites with different reinforcement architecture of SiC particles. Compos. Sci. Technol. 2006, 66, 2206-2217. [CrossRef]

41. Huu, T.; Requena, G.; Degischer, P. Thermal expansion behaviour of aluminum matrix composites with densely packed SiC particles. Compos. Part A Appl. Sci. Manuf. 2008, 39, 856-865. [CrossRef]

42. Jeyasimman, D.; Sivaprasad, K.; Sivasankaran, S.; Narayanasamy, R. Fabrication and consolidation behavior of Al 6061 nanocomposite powders reinforced by multi-walled carbon nanotubes. Powder Technol. 2014, 258, 189-197. [CrossRef]

43. Rashad, M.; Pan, F.; Tang, A.; Asif, M.; Aamir, M. Synergetic effect of graphene nanoplatelets (GNPs) and multi-walled carbon nanotube (MW-CNTs) on mechanical properties of pure magnesium. J. Alloy. Compd. 2014, 603, 111-118. [CrossRef]

44. Nie, K.B.; Wang, X.J.; Xu, L.; Wu, K.; Hu, X.S.; Zheng, M.Y. Influence of extrusion temperature and process parameter on microstructures and tensile properties of a particulate reinforced magnesium matrix nanocomposite. Mater. Des. 2012, 36, 199-205. [CrossRef]

45. Gaspera, E.D.; Tucker, R.; Star, K.; Lan, E.H.; Ju, Y.S.; Dunn, B. Copper-Based Conductive Composites with Tailored Thermal Expansion. ACS Appl. Mater. Interfaces 2013, 5, 10966-10974. [CrossRef] [PubMed]

46. Varol, T.; Canakci, A. The effect of type and ratio of reinforcement on the synthesis and characterization Cu-based nanocomposites by flake powder metallurgy. J. Alloy. Compd. 2015, 649, 1066-1074. [CrossRef]

47. Tang, Y.; Yang, X.; Wang, R.; Li, M. Enhancement of the mechanical properties of graphene-copper composites with graphene-nickel hybrids. Mater. Sci. Eng. A 2014, 599, 247-254. [CrossRef]

48. Rana, R.S.; Purohit, R.; Das, S. Review of recent Studies in Al matrix composites. Int. J. Sci. Eng. Res. 2012, 3, $1-16$.

49. Hu, H.; Kong, J. Improved Thermal Performance of Diamond-Copper Composites with Boron Carbide Coating. J. Mater. Eng. Perform. 2014, 23, 651-657. [CrossRef]

50. Zhang, D.; Zhan, Z. Preparation of graphene nanoplatelets-copper composites by a modified semi-powder method and their mechanical properties. J. Alloy. Compd. 2016, 658, 663-671. [CrossRef]

51. Kielbus, A.; Rzychon, T.; Przeliorz, R. DSC and Microstructural Investigations of The Elektron 21 Magnesium Alloy. Mater. Sci. Forum 2010, 642, 1447-1452. [CrossRef] 
52. Katsarou, L.; Mounib, M.; Lefebvre, W.; Vorozhtsov, S.; Pavese, M.; Badini, C.; Molina-aldareguia, J.M.; Cepeda, C.; MariaTeresa, P.P.; Dieringa, H. Microstructure, mechanical properties and creep of magnesium alloy Elektron21 reinforced with AlN nanoparticles by ultrasound-assisted stirring. Mater. Sci. Eng. A 2016, 659, 84-92. [CrossRef]

53. Chen, X. Fabrication and Properties of Particulate reinforced Aluminum Matrix Composites by Spontaneous Infiltration. Ph.D. Thesis, Politecnico di Torino, Torino TO, Italy, 2013.

54. Kroto, H. Handbook of Chemistry and Physics, 84th ed.; Lide, D.R., Ed.; CRC Press: Boca Raton, FL, USA, 2003.

55. Nishida, Y. Introduction to Metal Matrix Composites: Fabrication and Recycling; Springer: New York, NY, USA, 2013.

56. Cardarelli, F. Materials Handbook: A Coincise Desktop Reference; Springer: New York, NY, USA, 2008.

57. Srinivasan, M. Non-Oxide Materials: Applications and Engineering; Springer: Dordrecht, The Netherlands, 1996; pp. 3-42.

58. Safdari, M. A Computational and Experimental Study on the Electrical and Thermal Properties of Hybrid Nanocomposites Based on Carbon Nanotubes and Graphite Nanoplatelets. Ph.D. Thesis, Virginia Polytechnic Institute and State University, Blacksburg, VA, USA, 2012.

59. Novoselov, K.S.; Geim, A.K.; Morozov, S.V.; Al, E. Electric Field Effect in Atomically Thin Carbon Films. Science 2004, 306, 666-669. [CrossRef] [PubMed]

60. Kim, H.; Abdala, A.A.; Macosko, C.W. Graphene/Polymer Nanocomposites. Macromolecules 2010, 43, 6515-6530. [CrossRef]

61. Rollings, E.; Gweon, G.-H.; Zhou, S.Y.; Mun, B.S.; McChesney, J.L.; Hussain, B.S.; Fedorov, A.V.; First, P.N.; de Heer, W.A.; Lanzara, A. Synthesis and characterization of atomically thin graphite films on a silicon carbide substrate. J. Phys. Chem. Solids 2006, 67, 2172-2177. [CrossRef]

62. Wang, X.; You, H.; Liu, F.; Li, M.; Wan, L.; Li, S.; Li, Q.; Xu, Y.; Tian, R.; Yu, Z.; et al. Large-Scale Synthesis of Few-Layered Graphene using CVD. Chem. Vap. Depos. 2009, 15, 5356. [CrossRef]

63. Kosynkin, D.V.; Higginbotham, A.L.; Sinitskii, A.; Lomeda, J.R.; Dimiev, A.; Price, B.K.; Tour, J.M. Longitudinal unzipping of carbon nanotubes to form graphene Nanoribbons. Nature 2009, 458, 872-876. [CrossRef] [PubMed]

64. Shen, J.; Hu, Y.; Li, C.; Qin, C.; Shi, M.; Ye, M. Layer-by-Layer Self-Assembly of Graphene Nanoplatelets. Langmuir 2009, 25, 6122-6128. [CrossRef] [PubMed]

65. Jang, B.; Zhamu, A. Processing of nanographene platelets (NGPs) and NGP nanocomposites: A review. J. Mater. Sci. 2008, 43, 5092-5101. [CrossRef]

66. Fukushima, H.; Drzal, L.; Rook, B.; Rich, M. Thermal conductivity of exfoliated graphite nanocomposites. J. Therm. Anal. Calorim. 2006, 85, 235-238. [CrossRef]

67. Stankovich, S.; Dikin, D.A.; Dommett, G.H.B.; Kohlhaas, K.M.; Zimney, E.J.; Stach, E.A.; Piner, R.D.; Nguyen, S.T.; Ruoff, R.S. Graphene-based composite materials. Nature 2006, 442, 282-286. [CrossRef] [PubMed]

68. Bartolucci, S.F.; Paras, J.; Rafiee, M.A.; Rafiee, J.; Lee, S.; Kapoor, D.; Koratkar, N. Graphene-aluminum nanocomposites. Mater. Sci. Eng. A 2011, 528, 7933-7937. [CrossRef]

69. Saboori, A.; Moheimani, S.K.; Pavese, M.; Badini, C.; Fino, P. New nanocomposite materials with improved mechanical strength and tailored coefficient of thermal expansion for electro-packaging applications. Metals 2017, 7. [CrossRef]

70. Saboori, A.; Pavese, M.; Badini, C.; Fino, P. Microstructure and thermal conductivity of Al-Graphene composites fabricated by powder metallurgy and hot rolling techniques. Acta Metall. Sin. Engl. Lett. 2017, 30, 675-687. [CrossRef]

71. Hwang, J.; Yoon, T.; Jin, S.H.; Lee, J.; Kim, T.-S.; Hong, S.H.; Jeon, S. Enhanced Mechanical Properties of Graphene/Copper Nanocomposites Using a Molecular-Level Mixing Process. Adv. Mater. 2013, 25, 6724-6729. [CrossRef] [PubMed]

72. Wang, F.; Arai, S.; Endo, M. Metallization of multi-walled carbon nanotubes with copper by an electroless deposition process. Electrochem. Commun. 2004, 6, 1042-1044. [CrossRef]

73. Jiang, L.; Gao, L. Modified carbon nanotubes: An effective way to selective attachment of gold nanoparticles. Carbon 2003, 41, 2923-2929. [CrossRef] 
74. Chin, K.C.; Gohel, A.; Chen, W.Z.; Elim, H.I.; Ji, W.; Chong, G.L.; Sow, C.H.; Wee, A.T.S. Gold and silver coated carbon nanotubes: An improved broad-band optical limiter. Chem. Phys. Lett. 2005, 409, 85-88. [CrossRef]

75. Karches, M.; von Rohr, P.R. Microwave plasma characteristics of a circulating fluidized bed-plasma reactor for coating of powders. Surf. Coat. Technol. 2001, 142-144, 28-33. [CrossRef]

76. Kouadri-Mostefa, S.; Serp, P.; Hémati, M.; Caussat, B. Silicon Chemical Vapor Deposition (CVD) on microporous powders in a fluidized bed. Powder Technol. 2001, 120, 82-87. [CrossRef]

77. Dag, S.; Durgun, E.; Ciraci, S. High-conducting magnetic nanowires obtained from uniform titanium-covered carbon nanotubes. Phys. Rev. B 2004, 69, 121407. [CrossRef]

78. Zhang, Y.; Franklin, N.W.; Chen, R.J.; Dai, H. Metal coating on suspended carbon nanotubes and its implication to metal-tube interaction. Chem. Phys. Lett. 2000, 331, 35-41. [CrossRef]

79. Rashad, M.; Pan, F.; Yu, Z.; Asif, M. Investigation on microstructural, mechanical and electrochemical properties of aluminum composites reinforced with graphene nanoplatelets. Prog. Nat. Sci. Mater. Int. 2015, 25, 460-470. [CrossRef]

80. Rashad, M.; Pan, F.; Tang, A.; Asif, M. Effect of Graphene Nanoplatelets addition on mechanical properties of pure aluminum using a semi-powder method. Prog. Nat. Sci. Mater. Int. 2014, 24, 101-108. [CrossRef]

81. Saboori, A.; Pavese, M.; Badini, C.; Fino, P. Effect of Sample Preparation on the Microstructural Evaluation of Al-GNPs Nanocomposites. Metall. Microstruct. Anal. 2017, 6, 619-622. [CrossRef]

82. Van der Zwan, J.; Siskens, C.A.M. The compaction and mechanical properties of agglomerated materials. Powder Technol. 1982, 33, 43-54. [CrossRef]

83. Padmavathi, C.; Upadhyaya, A. Densification, Microstructure and Properties of Supersolidus Liquid Phase Sintered 6711Al-SiC Metal Matrix Composites. Sci. Sinter. 2010, 42, 363-382. [CrossRef]

84. Balshin, M.; Metalloprom, V. Theory Compact. Vestnik Metalloprom 1938, 18, 124-137.

85. Heckel, R.W. Density-Pressure Relationships in Powder Compaction. Trans. Metall. Soc. AIME 1961, 221, 671-675.

86. Walker, E.E. The properties of powders. Part VI. The compressibility of powders. Trans. Faraday Soc. 1923, 19, 73-82. [CrossRef]

87. Cooper, A.R.; EatonEato, L.E. Compaction behaviour of some ceramic powders. J. Am. Ceram. Soc. 1962, 45, 97-101. [CrossRef]

88. Kawakita, K.; Ludde, K. Some considerations on powder compression equations. Powder Technol. 1971, 4, 61-68. [CrossRef]

89. Panelli, R.; Filho, F.A. A study of a new phenomenological compacting equation. Powder Technol. 2001, 114, 255-261. [CrossRef]

90. Ge, R. A new powder compaction equation. Int. J. Powder Metall. 1991, 27, 211-216.

91. Doraivelu, S.M.; Gegel, H.L.; Gunasekera, J.S.; Malas, J.C.; Morgan, J.T.; Thomas, J.F., Jr. A new yield function for compressible P M materials. Int. J. Mech. Sci. 1984, 26, 527-535. [CrossRef]

92. Fleck, N.A.; Kuhn, L.T.; McMeeking, R.M. Yielding of Metal Powder Bonded by Isolated Contacts. Phys. Solids 1992, 40, 1139-1162. [CrossRef]

93. Hesabi, Z.R.; Hafizpour, H.R.; Simchi, A. An investigation on the compressibility of aluminum/nano-alumina composite powder prepared by blending and mechanical milling. Mater. Sci. Eng. A 2007, 454, 89-98. [CrossRef]

94. Saboori, A.; Novara, C.; Pavese, M.; Badini, C.; Giorgis, F.; Fino, P. An Investigation on the Sinterability and the Compaction Behavior of Aluminum/Graphene Nanoplatelets (GNPs) Prepared by Powder Metallurgy. J. Mater. Eng. Perform. 2017, 26, 993-999. [CrossRef]

95. Rashad, M.; Pan, F.; Tang, A.; Asif, M.; Hussain, S.; Gou, J.; Mao, J. Improved strength and ductility of magnesium with addition of aluminum and graphene nanoplatelets (Al + GNPs) using semi powder metallurgy method. J. Ind. Eng. Chem. 2015, 23, 243-250. [CrossRef]

96. Chen, Y.; Zhang, X.; Liu, E.; He, C.; Shi, C.; Li, J.; Nash, P.; Zhao, N. Fabrication of in-situ grown graphene reinforced Cu matrix composites. Sci. Rep. 2016, 6, 19363. [CrossRef] [PubMed]

97. Saboori, A.; Pavese, M.; Badini, C.; Fino, P. Development of Al- and Cu-based nanocomposites reinforced by graphene nanoplatelets: Fabrication and characterization. Front. Mater. Sci. 2017, 11, 171-181. [CrossRef]

98. Laha, T.; Kuchibhatla, S.; Seal, S.; Li, W.; Agarwal, A. Interfacial phenomena in thermally sprayed multiwalled carbon nanotube reinforced aluminum nanocomposite. Acta Mater. 2007, 55, 1059-1066. [CrossRef] 
99. Ci, L.; Ryu, Z.; Jin-Phillipp, N.Y.; Rühle, M. Investigation of the interfacial reaction between multi-walled carbon nanotubes and aluminum. Acta Mater. 2006, 54, 5367-5375. [CrossRef]

100. Kwon, H.; Estili, M.; Takagi, K.; Miyazaki, T.; Kawasaki, A. Combination of hot extrusion and spark plasma sintering for producing carbon nanotube reinforced aluminum matrix composites. Carbon 2009, 47, 570-577. [CrossRef]

101. Deng, C.F.; Zhang, X.X.; Wang, D.Z.; Ma, Y.X. Calorimetric study of carbon nanotubes and aluminum. Mater. Lett. 2007, 61, 3221-3223. [CrossRef]

102. Deng, C.F.; Wang, D.Z.; Zhang, X.X.; Li, A.B. Processing and properties of carbon nanotubes reinforced aluminum composites. Mater. Sci. Eng. A 2007, 444, 138-145. [CrossRef]

103. Kuzumaki, T.; Miyazawa, K.; Ichinose, H.; Ito, K. Processing of Carbon Nanotube Reinforced Aluminum Composite. J. Mater. Res. 1998, 13, 2445-2449. [CrossRef]

104. George, R.; Kashyap, K.T.; Rahul, R.; Yamdagni, S. Strengthening in carbon nanotube/aluminium (CNT/Al) composites. Scr. Mater. 2005, 53, 1159-1163. [CrossRef]

105. Pérez-Bustamante, R.; Estrada-Guel, I.; Antúnez-Flores, W.; Miki-Yoshida, M.; Ferreira, P.J.; Martínez-Sánchez, R. Novel Al-matrix nanocomposites reinforced with multi-walled carbon nanotubes. J. Alloy. Compd. 2008, 450, 323-326. [CrossRef]

106. Kwon, H.; Park, D.H.; Silvain, J.F.; Kawasaki, A. Investigation of carbon nanotube reinforced aluminum matrix composite materials. Compos. Sci. Technol. 2010, 70, 546-550. [CrossRef]

107. Schniepp, H.C.; Li, J.-L.; McAllister, M.J.; Sai, H.; Herrera-Alonso, M.; Adamson, D.H.; Prud'homme, R.K.; Car, R.; Saville, D.A.; Aksay, I.A. Functionalized Single Graphene Sheets Derived from Splitting Graphite Oxide. J. Phys. Chem. B 2006, 110, 8535-8539. [CrossRef] [PubMed]

108. Rafiee, M.A.; Rafiee, J.; Srivastava, I.; Wang, Z.; Song, H.; Yu, Z.-Z.; Koratkar, N. Fracture and Fatigue in Graphene Nanocomposites. Small 2010, 6, 179-183. [CrossRef] [PubMed]

109. Saboori, A. Metal Matrix Nanocomposites; Potentials, Challenges and Feasible Solutions. Ph.D. Thesis, Politecnico di Torino, Torino TO, Italy, 2017.

110. Saboori, A.; Pietroluongo, M.; Pavese, M.; Badini, C.F.; Fino, P. Influence of Graphene nanoplatelets (GNPs) on compressibility and sinterability of $\mathrm{Al}$ matrix nanocomposites prepared by powder metallurgy. In World PM2016; EPMA: Hamburg, Germany, 2016; p. 8.

111. Saboori, A.; Pavese, M.; Badini, C.; Fino, P. A Novel Cu-GNPs Nanocomposite with Improved Thermal and Mechanical Properties. Acta Metall. Sin. Engl. Lett. 2017. [CrossRef]

112. Shin, S.E.; Choi, H.J.; Shin, J.H.; Bae, D.H. Strengthening behavior of few-layered graphene/aluminum composites. Carbon 2014, 82, 143-151. [CrossRef]

113. Bakshi, S.R.; Agarwal, A. An analysis of the factors affecting strengthening in carbon nanotube reinforced aluminum composites. Carbon 2011, 49, 533-544. [CrossRef]

114. Chawla, N.; Shen, Y. Mechanical Behavior of Particle Reinforced Metal Matrix Composites. Adv. Eng. Mater. 2001, 3, 357-370. [CrossRef]

115. Song, S.G.; Shi, N.; Gray, G.T.; Roberts, J.A. Reinforcement shape effects on the fracture behavior and ductility of particulate-reinforced 6061-Al matrix composites. Metall. Mater. Trans. A 1996, 27, 3739-3746. [CrossRef]

116. Akhtar, F.; Javid, S.; Ali, K.; Du, X.; Guo, S. Microstructure, mechanical properties, electrical conductivity and wear behavior of high volume TiC reinforced Cu-matrix composites. Mater. Charact. 2009, 60, 327-336. [CrossRef]

117. Goli, P.; Ning, H.; Li, X.; Lu, C.Y.; Novoselov, K.S.; Balandin, A.A. Thermal Properties of Graphene-Copper-Graphene Heterogeneous Films. NANO Lett. 2014, 14, 1497-1503. [CrossRef] [PubMed]

118. Arnaud, C.; Lecouturier, F.; Mesguich, D.; Ferreira, N.; Chevallier, G.; Estournès, C.; Weibel, A.; Laurent, C. High strength-High conductivity double-walled carbon nanotube-Copper composite wires. Carbon 2016, 96, 212-215. [CrossRef]

119. Moustafa, S.F.; El-Badry, S.A.; Sanad, A.M.; Kieback, B. Friction and wear of copper-graphite composites made with Cu-coated and uncoated graphite powders. Wear 2002, 253, 699-710. [CrossRef]

120. Moustafa, S.F.; El-Badry, S.A.; Sanad, A.M. Effect of Graphite with and Without Copper Coating on Consolidation Behaviour and Sintering of Copper-Graphite Composite. Powder Metall. 1997, 40, 201-206. [CrossRef] 
121. Yao, G.C.; Mei, Q.S.; Li, J.Y.; Li, C.L.; Ma, Y.; Chen, F.; Liu, M. Cu/C composites with a good combination of hardness and electrical conductivity fabricated from $\mathrm{Cu}$ and graphite by accumulative roll-bonding. Mater. Des. 2016, 110, 124-129. [CrossRef]

122. Zhao, S.; Zheng, Z.; Huang, Z.; Dong, S.; Luo, P.; Zhang, Z.; Wang, Y. Cu matrix composites reinforced with aligned carbon nanotubes: Mechanical, electrical and thermal properties. Mater. Sci. Eng. A 2016, 675, 82-91. [CrossRef]

123. Tu, J.P.; Rong, W.; Guo, S.Y.; Yang, Y.Z. Dry sliding wear behavior of in situ Cu-TiB2 nanocomposites against medium carbon steel against medium carbon steel. Wear 2003, 255, 832-835. [CrossRef]

124. Nadkarni, A.V.; Samal, P.K.; Synk, J.E. Dispersion strengthened metal composites. U.S. Patent 4,752,334, 21 June 1988.

125. Dorri Moghadam, A.; Schultz, B.F.; Ferguson, J.B.; Omrani, E.; Rohatgi, P.K.; Gupta, N. Functional Metal Matrix Composites: Self-lubricating, Self-healing, and Nanocomposites-An Outlook. JOM 2014, 66, 872-881. [CrossRef]

(C) 2018 by the authors. Licensee MDPI, Basel, Switzerland. This article is an open access article distributed under the terms and conditions of the Creative Commons Attribution (CC BY) license (http://creativecommons.org/licenses/by/4.0/). 